
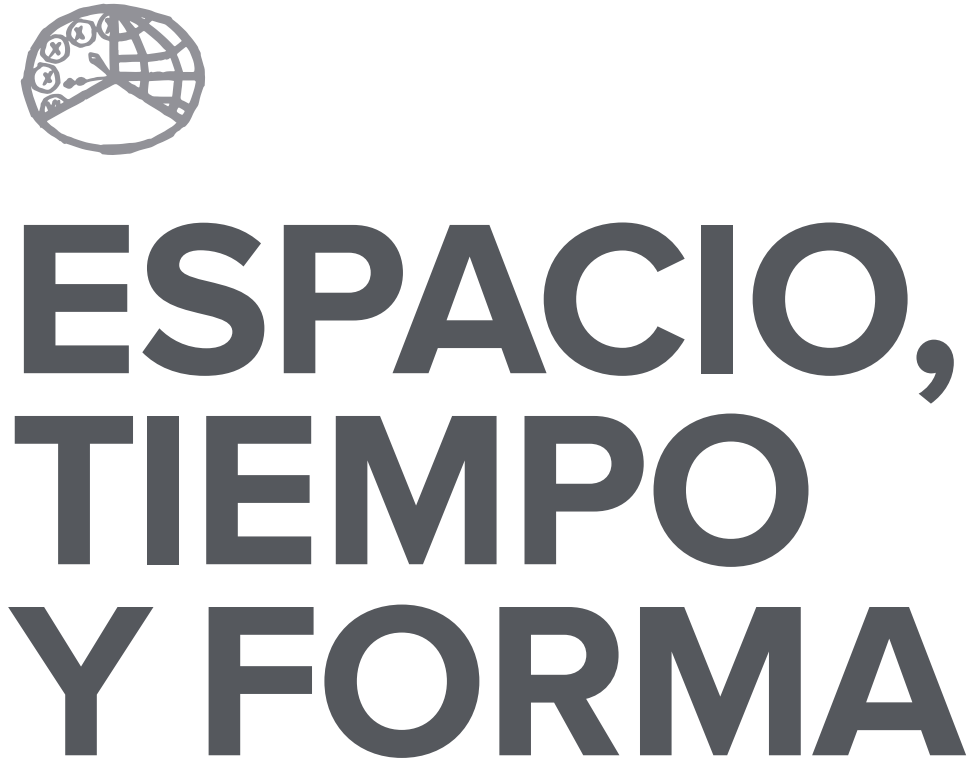

AÑO 2021

ISSN 0214-9745

E-ISSN 2340-1362

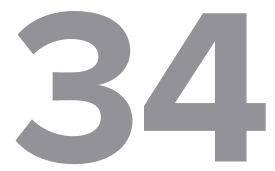

SERIE III HISTORIA MEDIEVAL

REVISTA DE LA FACULTAD DE GEOGRAFÍA E HISTORIA

VOLUMEN I 


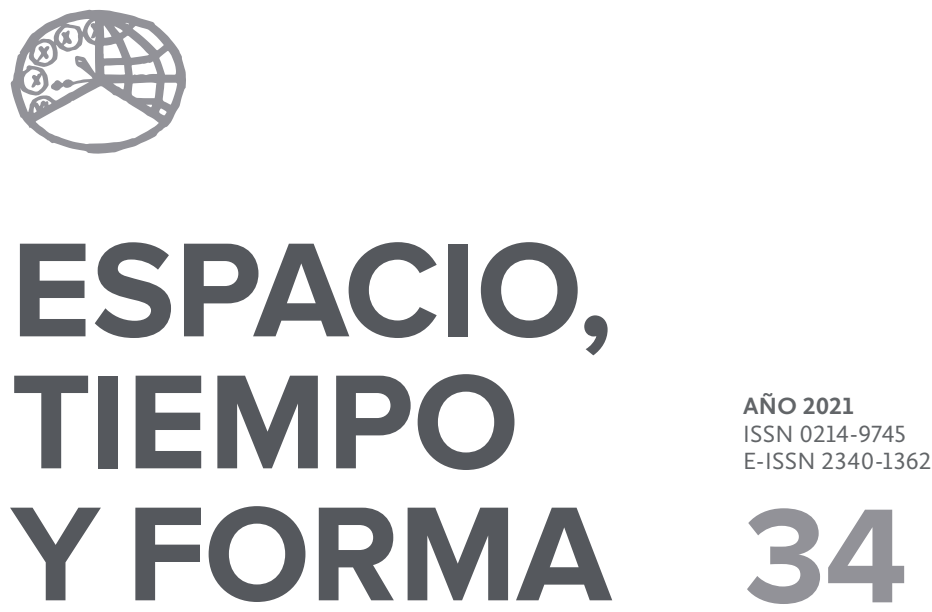

SERIE III HISTORIA MEDIEVAL

REVISTA DE LA FACULTAD DE GEOGRAFÍA E HISTORIA

VOLUMEN I

http://dx.doi.org/10.5944/etfiii.34.2021

\section{UกED}

UNIVERSIDAD NACIONAL DE EDUCACIÓN A DISTANCIA 
La revista Espacio, Tiempo y Forma (siglas recomendadas: ETF),

de la Facultad de Geografía e Historia de la UNED, que inició su publicación el año 1988, está organizada de la siguiente forma:

$$
\begin{aligned}
& \text { SERIE I - Prehistoria y Arqueología } \\
& \text { SERIE II - Historia Antigua } \\
& \text { SERIE III - Historia Medieval } \\
& \text { SERIE IV - Historia Moderna } \\
& \text { SERIE V - Historia Contemporánea } \\
& \text { SERIE VI - Geografía } \\
& \text { SERIE VII - Historia del Arte }
\end{aligned}
$$

Excepcionalmente, algunos volúmenes del año 1988 atienden a la siguiente numeración:
N. ${ }^{\circ} 1 \quad-$ Historia Contemporánea
N. ${ }^{\circ} 2-$ Historia del Arte
N. ${ }^{\circ} 3-$ Geografía
N. ${ }^{\circ} 4 \quad-$ Historia Moderna

ETF no se solidariza necesariamente con las opiniones expresadas por los autores.

UNIVERSIDAD NACIONAL DE EDUCACIÓN A DISTANCIA

Madrid, 2021

SERIE III - HISTORIA MEDIEVAL N. ${ }^{\circ} 34,2021$

ISSN 0214-9745 · E-ISSN 2340-1362

DEPÓSITO LEGAL M-21037-1988

URL: ETF III · HISTORIA MEDIEVAL · http://revistas.uned.es/index.php/ETFIII

DISEÑO Y COMPOSICIÓN

Carmen Chincoa Gallardo · http://www.laurisilva.net/cch

Impreso en España $\cdot$ Printed in Spain 
Espacio, Tiempo y Forma. Serie III. Historia Medieval es la revista científica fundada en I988 que publica el Departamento de Historia Medieval y Ciencias y Técnicas Historiográficas de la Facultad de Geografía e Historia de la UNED. Está dedicada al estudio de la Historia Medieval y acoge trabajos inéditos de investigación, en especial artículos que constituyan una aportación novedosa, que enriquezcan el campo de estudio que abordan y que ofrezcan una perspectiva de análisis crítico. Va dirigida preferentemente a la comunidad científica y universitaria, tanto nacional como internacional, así como a todos los profesionales de la Historia Medieval en general. Su periodicidad es anual y se somete al sistema de revisión por pares ciegos. La revista facilita el acceso sin restricciones a todo su contenido desde el momento de su publicación en edición electrónica. Espacio, Tiempo y Forma. Serie III. Historia Medieval se publica en formato electrónico y en papel.
Espacio, Tiempo y Forma. Serie III. Historia Medieval (Space, Time and Form. Series III. Medieval History) is a peerreviewed academic journal founded in I988 and published by the Department of Medieval History and Historiographical Sciences and Techniques at the Faculty of Geography and History, UNED. It is devoted to the study of Medieval History and is addressed to the Spanish and international scholarly community, as well as to professionals in the field of Medieval History. The journal welcomes previously unpublished articles, particularly works that provide an innovative approach, contribute to its field of research and offer a critical analysis. It is published annually. The journal provides complete open access to its content available online upon publication. Espacio, Tiempo y Forma. Serie III. Historia Medieval is published online and in print and is indexed in the databases and directories enumerated below.

Espacio, Tiempo y Forma. Serie III. Historia Medieval está registrada e indexada en Repertorios Bibliográficos y Bases de Datos nacionales e internacionales, como recomiendan los criterios de la Comisión Nacional Evaluadora de la Actividad Investigadora: LATINDEX, DICE, ISOC (CINDOC), RESH, INRECH, Dialnet, e-spacio UNED, CIRC 2.o (20I6), MIAR, FRANCIS, PIO, Ulrich's, SUDOC, ZDB, ERIH (ESF), REDIB, Repertorio de Medievalismo Hispánico, Directory of Open Access Journals (DOAJ), Emerging Sources Citation Index (ESCI), SCOPUS. La revista ha obtenido el Sello de Calidad de la FECYT (2018).

\section{EQUIPO EDITORIAL}

Edita: Departamento de Historia Medieval y Ciencias y Técnicas Historiográficas, Universidad Nacional de Educación a Distancia

Director del Consejo de Redacción: Enrique Cantera Montenegro (UNED)

Editores: Enrique Cantera Montenegro (UNED), Carlos Barquero Goñi (UNED) 
CONSEJO DE REDACCIÓN

Cristina Álvarez Millán

Departamento de Historia Medieval y Ciencias y Técnicas Historiográficas, UNED

Ana Arranz Guzmán

Universidad Complutense de Madrid

Carlos de Ayala Martínez

Universidad Autónoma de Madrid

Carlos Barquero Goñi

Departamento de Historia Medieval y Ciencias y Técnicas Historiográficas, UNED

Enrique Cantera Montenegro

Departamento de Historia Medieval y Ciencias y Técnicas Historiográficas, UNED

Ana Echevarría Arsuaga

Departamento de Historia Medieval y Ciencias y Técnicas Historiográficas, UNED

José María de Francisco Olmos

Universidad Complutense de Madrid

María Jesús Fuente Pérez

Universidad Carlos III de Madrid

Manuel Fernando Ladero Quesada

Departamento de Historia Medieval y Ciencias y Técnicas Historiográficas, UNED

Paulina López Pita

Departamento de Historia Medieval y Ciencias y Técnicas Historiográficas, UNED

José Miguel López Villalba

Departamento de Historia Medieval y Ciencias y Técnicas Historiográficas, UNED

José María Monsalvo Antón

Universidad de Salamanca

Isabel Montes Romero-Camacho

Universidad de Sevilla

Gonzalo Viñuales Ferreiro

Universidad Rey Juan Carlos

COMITÉ CIENTÍFICO

Vicente Ángel Álvarez Palenzuela

Universidad Autónoma de Madrid

Daniel Baloup

Université de Toulouse-Le Mirail

Vicente García Lobo

Universidad de León

María Estela González de Fauve

Universidad de Buenos Aires · Fundación para la Historia de España

César González Mínguez

Universidad del País Vasco 
Nikolas Jaspert

Ruhr-Universität Bochum, Alemania

DIRECTORA DE ETF SERIES I-VII

Yayo Aznar Almazán

Decana Facultad de Geografía e Historia, UNED

SECRETARIO DE ETF SERIES I-VII

Julio Fernández Portela

Departamento de Geografía, UNED

GESTORA PLATAFORMA OJS

Carmen Chincoa Gallardo

COMITÉ EDITORIAL DE ETF SERIES I-VII

Carlos Barquero Goñi, Departamento de Historia Medieval y Ciencias y Técnicas Historiográficas, UNED; Enrique Cantera Montenegro, Departamento de Historia Medieval y Ciencias y Técnicas Historiográficas, Uned; Pilar Díez del Corral Corredoira, Departamento de Historia del Arte, UneD; Carmen Guiral Pelegrín, Departamento de Prehistoria y Arqueología (Arqueología), Uned; Patricia Hevia Gómez, Departamento de Prehistoria y Arqueología (Arqueología), unED; Luiza lordache Cârstea, Departamento de Historia Contemporánea, UNED; M. ${ }^{a}$ Luisa de Lázaro Torres, Departamento de Geografía, Uned; David Martín Marcos, Departamento de Historia Moderna, Uned; José Antonio Martínez Torres, Departamento de Historia Moderna, UnED; Íñigo García Martínez de Lagrán, Departamento de Prehistoria y Arqueología (Prehistoria), UnED; Álvaro Molina Martín, Departamento de Historia del Arte, Uned; Francisco Javier Muñoz Ibáñez, Departamento de Prehistoria y Arqueología (Prehistoria), UNED; Rocío Negrete Peña, Departamento de Historia Contemporánea, UnED; Miguel Ángel Novillo López, Departamento de Historia Antigua, UnED.

CORRESPONDENCIA

Revista Espacio, Tiempo y Forma

Facultad de Geografía e Historia, UNED

c/ Senda del Rey, 7

28040 Madrid

e-mail: revista-etf@geo.uned.es 



\section{SUMARIO · SUMMARY}

\section{VOLUMEN I}

13 Artículos $\cdot$ Articles

15 Patricia A. Argüelles Álvarez

Peligros, inseguridades y problemas del viajero visigodo

Danger, Lack of Safety and Problems for the Visigothic Traveller

37 Carmen Barceló, Ana labarta, Josep Benedito \& José M. Melchor Cuatro cerámicas con epigrafía árabe del Museu de Borriana

Four Ceramic Pieces with Arabic Inscriptions in the Archeological Museum of Borriana

65 Carlos Barquero Goñ

Organización de la Orden de San Juan en Castilla durante los siglos XII y XIII The Organization of the Order of Saint John in Castile during the Twelfth and Thirteenth Centuries

113 Francisco de Paula Cañas Gálvez

Una infanta de Navarra en la corte de Castilla: escenarios políticos en torno a la configuración y evolución del Hostal y la casa de Blanca de Trastámara, Princesa de Asturias (I424-†I464)

A Princess of Navarre in the Court of Castile: Political Scenarios in the Configuration and Evolution of the Hostal and Royal Household of Blanca of Trastámara, Princess of Asturias (I424-†I464)

165 David Caramazana Malia

Las promociones artísticas de Alonso de Ejea, arzobispo y administrador perpetuo de la Archidiócesis de Sevilla y patriarca de Constantinopla (I403-I4I7)

The Artistic Patronage of Alonso de Ejea, Archbishop and Perpetual Administrator of the Archdiocese of Seville and Patriarch of Constantinople (I403-I4I7) 
203 Pedro Castillo Maldonado

Privilegios episcopales: la inviolabilidad de los obispos visigóticos y el delito de lesa majestad

Episcopal Privileges: The Inviolability of Visigothic Bishops and the Crime of Lèse-Majesté

227 Máximo Diago HERnANDO

Alonso de Fonseca, Obispo de Ávila, Cuenca y Osma, y el ascenso de un linaje de exiliados portugueses en la Castilla de los siglos XV y XVI Alonso de Fonseca, Bishop of Ávila, Cuenca and Osma, and the Promotion in Castile of an Exiled Noble Family from Portugal during the Fifteenth and Sixteenth Centuries

263 Antonio PIO DI Cosmo

Santa Brigida ed il Monte Gargano: un paesaggio dell'anima. La descrizione dell'ambiente come stratagemma d'ammaestramento morale Saint Brigid and Mount Gargano: A Landscape of the Soul. The Description of the Environment as a Device for Moral Instruction

Santa Brígida y el Monte Gargano: un paisaje del alma. La descripción del medio ambiente como estrategia de entrenamiento moral

293 FERRAN ESQUiLACHE

La 'fila' de agua valenciana y otras medidas de aforo. La verdadera naturaleza de un sistema de medición de caudales de origen andalusí

The Valencian Water 'Fila' and other Systems of Gauging Liquid Capacity. The Actual Nature of a Measurement System of Water Flow of Andalusí Origin

323 Alejandro Esteban Álvarez

Habices del Reino de Granada averiguados en I528 y I53I: la țā‘a nazarí de Órgiva (Alpujarra)

Habices of the Kingdom of Granada Ascertained in 1528 and I53I: The Nasrid tạa'a of Órgiva (Alpujarra)

359 Javier Gómez Gómez e Iñakı Martín Viso

Rationes y decimas: evidencias sobre la gestión de las sernas en el siglo Xl en el noroeste de la Península Ibérica

Rationes and Decimas: Some Evidences on the Management of Eleventh Century Sernas in Northwestern Iberia 
383 Santiago González Sánchez

Aportaciones de Paredes de Nava a las campañas militares del Infante Don Fernando, señor de la villa y regente de Castilla, contra el Reino Nazarí de Granada en I407 y en I4IO

The Contribution of Paredes de Nava to the Military Campaigns of the Infante Fernando, Lord of the Town and Regent of Castile, against the Nasrid Kingdom of Granada in 1407 and I4IO

429 ANTONI LLIBRER ESCRIG

Una máquina para la industria medieval. Los batanes del sur valenciano: integración y negocio. Nuevas aportaciones (I49O-I502)

A Machine for Medieval Industry. The Fulling Mills of the Valencian South: Integration and Business. New contributions (I49O-I502)

455 José Miguel López Villalba

Comunicación escrita y oral de la ordenanza municipal (siglos XV-XVI) Written and Oral Communication of Municipal Regulations (FifteenthSixteenth Centuries)

501 Emilio Martín Gutiérrez

El aprovechamiento de los recursos naturales: la grana en Andalucía occidental durante el siglo XV

The Use of Natural Resources: Grana Pigmentin Western Andalusia during the Fifteenth Century

\section{VOLUMEN II}

537 Vera-Cruz Miranda Menacho

Las finanzas de un heredero: Carlos de Aragón y Navarra (I42I-I46I)

A Crown Prince's Finances: Charles of Aragon and Navarre (I42I-I46I)

569 Raúl Morales Muñoz

Hacia una revalorización del conciliarismo hispano bajomedieval: el Defensorium Trium Conclusionum de Alfonso de Madrigal

Towards a Reappraisal of Late-Medieval Hispanic Conciliarism: Alfonso de Madrigal's Defensorium Trium Conclusionum 
605 David Nogales Rincón

Enrique III de Castilla (I390-I406) y la indagación de rentas: un proyecto regio para la búsqueda de mineros y tesoros a inicios del cuatrocientos Enrique III of Castile (I390-I406) and the Inquiry into Sources of Revenue: A Royal Project for the Quest of Mines And Treasures at the Turn of the Fifteenth Century

647 Gonzalo Oliva Manso

Seisenes y novenes. Tiempos de calma para la moneda castellano-leonesa (I282-I3I2)

The Seisén and the Novén. Times of Stability for the Castile-Leonese Currency (I282-I3I2)

685 Alberto Peña Fernández y Manuel García Alonso Una inscripción medieval inédita en la iglesia de San Miguel de Aguayo (Cantabria)

A Newly Found Medieval Inscription in the Church of San Miguel de Aguayo (Cantabria)

713 Rodrigo Pousa Diéguez

Configuración institucional de una villa costera: Muros en el tránsito de la Edad Media a la Edad Moderna

The Institutional Development of a Coastal Village: Muros between the Middle Ages and the Early Modern Times

745 Juan A. Prieto Sayagués

Las profesiones femeninas de la nobleza y de las oligarquías urbanas en la Castilla bajomedieval. Causas, dinámicas, privilegios y donaciones

Female Professions among the Nobility and the Urban Oligarchy in Late Medieval Castile. Causes, Dynamics, Privileges and Donations

815 María del Pilar Rábade Obradó

El miedo a la Inquisición en la Castilla de los Reyes Católicos

Fear of the Inquisition in Castile under the Catholic Monarchs

845 Carlos Manuel Reglero de la Fuente

EL abad contra el rey (y los regidores): conflicto de jurisdicciones y ejercicio del poder en Sahagún (I398-I4I7)

The Abbot versus The King (and the Town Councillors): Conflict between Jurisdictions and the Use of Power in Sahagún (I398-I4I7) 
881 Manuel Alejandro Rodríguez de la Peña

Eusebius and Alcuin on Constantine and Charlemagne as Wise Rulers:

Sapiential Rulership in Late Antiquity and the Early Middle Ages

Constantino y Carlomagno como gobernantes sabios en la obra de Eusebio de Cesarea y Alcuino de York: la realeza sapiencial en la Antigüedad Tardía y la Alta Edad Media

915 Antonio SÁnchez González

El Archivo de los Mariscales de Castilla y Marqueses de Malagón

The Archives of the Marshals of Castile and the Marquises of Malagón

\section{Estudios y comentarios}

951 Serafín Olcoz Yanguas

Apostilla al estudio Influencia de las redes nobiliarias en la expansión cristiana del siglo XII: el caso de Soria (ETF, 33, 2020)

Notes on the Article The Influence of Aristocratic Networks on the Christian Expansion of the Twelfth Century. The Case of Soria $(E T F, 33,2020)$

\section{Libros $\cdot$ Books}

969 CASTRIllo CASAdo, Janire, Las mujeres vascas durante la Baja Edad Media (María Jesús Fuente)

973 Crónica del rey Juan II de Castilla. Minoría y primeros años de reinado (I406I420). Garcia, Michel (edición y estudio) (Víctor MuÑoz Gómez)

981 Da Silva, Marcelo Cândido, História Medieval (Diego Carlo Améndolla SPÍNOLA)

987 Galende Díaz, Juan Carlos y Ávila SeoAne, Nicolás, El rodado regio hispánico. Fernando III de León y Castilla (I23O-I252) (MAURicio Herrero JIMÉNEZ)

989 GARcía IzQuiERdo, Iván, Frontera, fuero y concejos. El valle del Riaza en la Edad Media (siglos VIII-XII) (CARLOS BARQUERO GOÑI)

993 García IzQuierdo, Iván y Peterson, David (coords.), Camino y Señorío. Obra selecta de Luis Martínez García (Enrique Cantera Montenegro) 
995 González Paz, Carlos Andrés, O Bispado de Mondoñedo na Idade Media. Territorio, comunidade e poder (ENRIQue CANTERA Montenegro)

997 López Martínez, Amalia, Minutarios notariales de Estevo Pérez (Ourense, siglo XIV) (José Miguel López Villalba)

999 Miranda García, Fermín y López de Guereño Sanz, María Teresa (eds.), La muerte de los príncipes en la Edad Media. Balance y perspectivas historiográficas (ANA Echevarría Arsuaga)

1003 Motis Dolader, Miguel Ángel, Vivencias, emociones y perfiles femeninos. Judeoconversas e Inquisición en Aragón en el siglo XV (ANA EcheVARRía ArSUAGA)

1007 Solórzano Telechea, Jesús Ángel y Martín Pérez, Fernando (coords.), Rutas de comunicación marítima y terrestre en los reinos hispánicos durante la Baja Edad Media. Movilidad, conectividad y gobernanza (ENRIQUe José Ruiz Pilares)

1013 Torre, Sandra de la - Etxeberria, Ekaitz - Díaz de Durana, José Ramón (coords.), Valer más en la tierra. Poder, violencia y linaje en el País Vasco bajomedieval (EnRIQue CANTERA Montenegro)

1015 TRIllo SAN José, Carmen, La Vega de Granada a partir de documentación árabe romanceada inédita (I457-I494). Estudio, edición e índices (INMACULADA GONZÁlez SopeÑA)

1019 Val Valdivieso, M. ${ }^{a}$ Isabel - Villanueva Zubizarreta, Olatz (Coords.), Pero Ansúrez. El conde, su época y su memoria (Enrique CANTERA Montenegro)

1021 Villanueva Morte, Concepción y Fernández de Córdova Miralles, Álvaro, El embajador Claver. Diplomacia y conflicto en las «Guerras de Italia» (I495-I504) (ENRIQUe CANTERA MONTENEGRO)

1023 Normas de publicación · Authors Guidelines 


\section{ARTÍCULOS · ARTICLES}

\section{VOLUMEN I}





\title{
PRIVILEGIOS EPISCOPALES: \\ LA INVIOLABILIDAD DE LOS \\ OBISPOS VISIGÓTICOS Y EL \\ DELITO DE LESA MAJESTAD
}

EPISCOPAL PRIVILEGES:

\section{THE INVIOLABILITY OF VISIGOTHIC BISHOPS AND THE CRIME OF LĖSE-MAJESTÉ}

Pedro Castillo Maldonado

Recepción: 2020/12/28 · Comunicación de observaciones de evaluadores: 2021/02/17 ·

Aceptación: 2021/03/12

DOI: https://dx.doi.org/10.5944/etfiii.34.2021.30041

\section{Resumen}

En estas páginas se señala cómo la naturaleza sagrada del sacerdocio, y por tanto su inviolabilidad, no puso a salvo de maltratos y violencias a los obispos visigóticos, pero sí evitó que se atentase contra sus vidas, al menos de forma pública y por los poderes públicos. Esta consideración adquiere relevancia en el caso de los delitos de lesa majestad, constituyendo un privilegio personal de importancia en el inestable Reino Visigodo.

\section{Palabras clave}

Antigüedad Tardía; Iglesia visigoda; privilegios episcopales; inviolabilidad; crimen de lesa majestad.

\begin{abstract}
In these pages we explain how the sacred nature of priesthood, and therefore its inviolability, did not prevent the Visigothic bishops from being mistreated and exposed to violence, but it did avoid assassination attempts on their lives, at least publicly and by public authorities. This consideration acquires relevance in the case of crimes of lèse-majesté, which made inviolability an important personal privilege in the unstable Visigothic Kingdom.
\end{abstract}

\section{Keywords}

Late Antiquity; Visigothic Church; Episcopal Privileges; Inviolability; Crime of lèse-majesté. 
n.t. 


\section{INTRODUCCIÓN}

Una ley del rey Recesvinto establece el precepto jurídico de que «ninguna persona ni ninguna dignidad constituida en poder - persona uel potentia dignitatisno se considere ajena a la custodia de las leyes». Se trata aquí de una custodia pasiva, el deber de sujetarse a la ley, que compete tanto a súbditos, obligados por la necesidad -inpellat necessitas-, como al monarca, por propia voluntad -principis uoluntas ${ }^{2}$.

El principio de necesidad se muestra con toda su fuerza en el caso de los delitos políticos. Ya Chindasvinto, un monarca que paradójicamente asciende al trono mediante un golpe de estado al alzarse contra el rey Tulga, había establecido penas de dureza extraordinaria para cualquiera -quicumque- que se fugue del Reino, conspire o perturbe su estabilidad, confabule con sus enemigos o contra la corona, y planee atentar o llegue a hacerlo contra la vida del monarca, en dictamen que recoge la recopilación legal ervigiana?

Pero los obispos no entran en la categoría de cualesquiera, ni como agentes sociales ni como sujetos de derecho. No son unos dirigentes más, y mucho menos unos súbditos comunes. El obispo es un compendio de honor, sublimitas, maiestas, uirtus, potestas..., de modo que a su auctoritas suma una particular dignitas. Sacerdote y epifanía de Dios en la tierra, tiene una naturaleza santa, sagrada ${ }^{4}$.

El orden sacerdotal conlleva tanto deberes como privilegios, entre éstos la terminante prohibición de atentar contra la persona del obispo, considerada sagrada y, por tanto, inviolable. En consecuencia, el obispo disfruta de un privilegio ad personam de importancia no menor dada la extraordinaria violencia socioeconómica del periodo y, en especial, la inestabilidad política crónica del Reino Visigodo.

\section{VIOLENCIAS Y DIGNIDAD EPISCOPAL}

Sin embargo, sería un error pensar que las vidas de los clérigos en general, y de los obispos en particular, discurren plácidamente en el Reino Visigodo, a salvo

2. L.V. II, 1, 2 (ed. y trad. Ramis Serra, Pedro y Ramis Barceló, Rafael: El libro de los Juicios (Liber ludicorum). Madrid, Boletín Oficial del Estado, 2015).

3. LV. II, 1,8 .

4. Creo innecesario incidir en este aspecto derivado de su condición sacerdotal. La consideración sagrada del obispo se remonta a los mismos orígenes de configuración del obispado monárquico y desde el siglo $V$ se generaliza que los obispos se dirijan a sí mismos con el título-epíteto de sanctus/sanctissimus. Abundan los textos tardoantiguos que enfatizan esta consideración supra-humana del obispo. Para Juan Crisóstomo los obispos pertenecen a las instituciones celestes, merecen más reverencia que los magistrados y reyes, y sus personas es como si hubiesen sido trasladados desde el cielo y despojados de la naturaleza humana: loan. Chris., Sac. III.4-6 (ed. PG 48). Naturalmente, esto no es incompatible con una profesionalización del sacerdocio. A los obispos se les exigen determinadas competencias y virtudes, entre estas últimas, como quiere Isidoro de Sevilla, ser santo, irreprensible en todo y ejemplo de vida: Is., Eccl. Off. II, 5 (ed. Lawson, Christopher M.: CCSL 113). 
de violencias y atentados contra sus personas. No faltan los ejemplos de maltratos y aún de muerte a mano airada, producto, eso sí, de la actuación de marginales, de siervos o, más comúnmente, de enfrentamientos internos entre eclesiásticos ${ }^{5}$.

En fechas tempranas, el concilio de Lérida del año 546, en un momento especialmente conflictivo para la provincia Tarraconense ${ }^{6}$, dispone el castigo por el obispo de los clérigos que intenten matarse mutuamente ${ }^{7}$. En Mérida, en la década de los años setenta o comienzos de los ochenta del siglo Vl, el abad Nancto es asesinado por los lugareños del predio que le ha regalado el rey Leovigido ${ }^{8}$. Y con el Reino católico ya instaurado, en la segunda década del siglo VII, el liberto Eliseo trata de envenenar a su patrono, el obispo Juan, además de realizar otras acciones dañinas (de las que nada sabemos) para la iglesia egabrense ${ }^{9}$. Eliseo pudo aprovechar un momento de desconcierto o de desgobierno en la diócesis, pues Juan sufría de una enfermedad ocular durante la cual se produjeron ordenaciones irregulares de presbíteros e incluso de obispos, según denuncia del diácono Aniano ante el concilio de Sevilla del año $6 \mathrm{Ig}^{\mathrm{IO}}$. Los reunidos en Sevilla, además de reintegrar en la esclavitud a Eliseo, no dudan en remover tales ordenaciones, preservando así la prerrogativa episcopal.

De lo agrio que podían ser las violencias entre gentes de religión es un buen indicio lo acontecido con Valerio del Bierzo, en unas fechas difíciles de determinar, pero acaso en torno al año $673^{\text {II }}$. El asceta sufre la hostilidad de los presbíteros Fayno y Justo, llegando este último a intentar degollarle ante el altar en el predio de Ebronanto ${ }^{12}$. Valerio se había opuesto a la ordenación de Justo, y seguramente éste no lo había olvidado.

5. También contamos con antecedentes tardorromanos de violencia religiosa. Es el caso del presbítero Vicente, brutalmente asesinado junto con sus fieles: Lib. Prec, (XX) 73-76 (ed. y trad. CANELLIS, Aline: SC 504). Al respecto, FeRNÁNDEZ UBIÑA, José: «El Libellus Precum y los conflictos religiosos en la Hispania de Teodosio», Florentia lliberritana, 8 (1997), pp. 103-123.

6. En el año 541 los francos Childerico y Clotario cruzaron los Pirineos, tomaron Pamplona, saquearon la Tarraconense y asediaron Zaragoza, y al año siguiente se desató una epidemia de peste inguinal: Greg. Tur, H.F. III, 29 (ed. MGHsrm I-1; trad. Herrera Roldán, Pedro: Gregorio de Tours. Historias. Cáceres, Universidad de Extremadura, 2013); Is., H.G., 41 (ed. y trad. Rodríguez Alonso, Cristóbal: Las Historias de los Godos, Vándalos y Suevos de Isidoro de Sevilla. León, Centro de Estudios e Investigación San Isidoro, 1975); Chron. Caes., ad. a. 541 y 542 (ed. MGHaa XI-2).

7. Conc. Ilerd., c. 11 (para los concilios, salvo indicación en contrario, ed. Martínez Díez, Gonzalo y Rodríguez, Félix: La Colección Canónica Hispana, vols. IV-VI. Madrid, CSIC, 1984-2002). Nótese que prevalece el priuilegium fori, más favorable para los acusados. Normalmente las causas criminales estaban excluidas de los tribunales eclesiásticos, por comportar sentencias de sangre: así, por ejemplo, Conc. Tarr., c. 4.

8. VSPE III, 44-61 (ed. MAYa SÁnchez, Antonio: CCSL 116; trad. Velázquez, Isabel: Vidas de los santos Padres de Mérida. Madrid, Trotta, 2008).

9. Conc. II Hisp., c. 8 (ed. y trad. VIVES, José: Concilios visigóticos e hispano-romanos. Barcelona-Madrid, CSIC, 1963). La actuación de Eliseo no parece tan deleznable si consideramos el trato que en ocasiones soportaban las familias in obsequio ecclesiae, con situaciones extremas que inducían al suicidio (Conc. XVI Tol., c. 4). Por otra parte, el concilio de Valencia dictamina que no se entierre el cadáver del obispo hasta la llegada del coepíscopo que había de oficiar los funerales (Conc. Val., c. 4), sin duda para que contase con un sepelio acorde a su dignidad y para evitar la depredación del patrimonio eclesiástico, pero acaso también como garantía ante eventuales violencias ocultas.

10. Conc. II Hisp., c. 5.

11. ORLANDIS, José: «Algunas consideraciones en torno a la circunstancia histórica de Valerio del Bierzo», Helmantica, 145-146 (1997), pp. 157-159.

12. Val., Ordo quer., 15 (ed. y trad. Díaz y Díaz, Manuel C.: Valerio del Bierzo. Su persona. Su obra. León, Centro de Estudios e Investigación San Isidoro, 2006). 
Por lo que respecta al orden episcopal, sabemos que un obispo llamado Justo muere en la primera mitad del siglo VIl estrangulado por sus subordinados ${ }^{13}$. El autor de esta noticia redactada entre los años 657 y 677 , y por tanto tras la muerte del mencionado obispo, Ildefonso de Toledo, insinúa que era una recta contrapartida al proceder de Justo, pues cuando era diácono, ensoberbecido, había insultado al obispo Eladio de Toledo y, siendo ya obispo, había enfermado, sus sentidos estaban alterados y se dejaba llevar por la intemperancia de sus costumbres. A diferencia de lo ocurrido en el pasado con el abad Nancto, hay que hacer notar que los asesinos de Justo no son siervos u otros dependientes procedentes de la familia ecclesiae. Ildefonso usa de una expresión genérica - a ministris altaris suicon la que designa, sin género de duda, a diversos grados eclesiásticos, esto es, presbíteros, diáconos y órdenes menores.

La iglesia de Toledo fue siempre especialmente conflictiva. Ildefonso narra cómo en el pasado, en la década de los años veinte del siglo Vl, el obispo Montano hizo una extraordinaria demostración para acallar a los calumniadores que le acusaban de mantener relaciones impuras: impartir la misa con unos carbones encendidos en su traje (posiblemente la estola pontifical) ${ }^{14}$, en una exhibición a medio camino entre el prodigium y la ordalía. E Ildefonso no duda en asimilar los tiempos remotos con otros más cercanos a su persona. En la década de los años treinta del siglo VIl, el presbítero Geroncio, con el apoyo de Sisenando, desprecia y hostiga al obispo Justo de Toledo. En ecuánime destino, Geroncio pierde sus facultades mentales ${ }^{15}$. En fin, de la convulsa vida eclesiástica de la capital regia es buena muestra que no falten los obispos que se distinguen por perseguir a sus clérigos. Es el caso del último obispo toledano, Sinderedo. Con el favor del rey Witiza, veja a los clérigos más longevos y es de creer que más prestigiosos de la diócesis ${ }^{16}$. No es de descartar que esta situación también contribuyese a su precipitada huida ante la llegada de los arabo-beréberes ${ }^{17}$.

Pese a todo, estas violencias siempre fueron motivo de escándalo. La preservación de la dignitas del ministerio y de la inviolabilidad de la persona del obispo es la norma. El respeto reverencial que se tiene por los obispos, casi sin importar su

13. Ild., Vir. II., praef. 36-40 (ed. y trad. Codoñer Merino, Carmen: El De Viris Illustribus de Ildefonso de Toledo. Estudio y edición crítica. Salamanca, Universidad de Salamanca, 1972). Sobre la difícil identificación de este Justo y su diferenciación con el obispo homónimo toledano suscriptor del concilio de Toledo del año 633, véase GARCía MORENO, Luis Agustín: Prosopografía del Reino Visigodo de Toledo. Salamanca, Universidad de Salamanca, 1974, n² 246, n. 2.

14. Ild., Vir. II., praef. 28-35.

15. Ild., Vir. II., praef. 41-47. Ildefonso no menciona el nombre del monarca.

16. Cont. Hisp., 69 (ed. MGHaa XI-2). Sobre las razones del proceder de Sinderedo, véase la hipótesis de García Moreno, Luis Agustín: España 702-719. La conquista musulmana. Sevilla, Universidad de Sevilla, 2013, pp. 82-85, según la cual el obispo sigue la política de Witiza de aceptación de los cánones del concilio in Trullo de los años 691-692, lo que necesariamente iba contra los uiri longeuos seguidores de la tradición eclesial occidental.

17. Comúnmente se entiende que parte hacia Roma, por su documentada presencia en un concilio romano. No obstante, IsLA Frez, Amancio: «Conflictos externos e internos en el fin del Reino Visigodo», Hispania: Revista española de historia, 211 (2002), p. 634, interpreta con buenas razones que la huida se produjo, al menos inicialmente, a territorio imperial. Sobre la posición política y religiosa de Sinderedo, GARCíA MORENO, Luis Agustín: España 702-719..., pp. 176-178. 
actuación y cumplimento de responsabilidades, es innegable. Los mismos obispos se habían encargado de hacerlo así, preservando de toda mácula a su propia dignidad y protegiendo a sus personas. Tal extremo se demuestra en el litigio entre los obispos astigitanos Marciano y Avencio. Marciano es depuesto de la sede y sustituido por Avencio en tiempos del rey Suintila ${ }^{\text {I8 }}$. Aprovechando el cambio de monarca, ahora Sisenando, en una primera apelación Marciano obtiene una reparación parcial del concilio de Toledo del año 636. Repuesto Marciano en el grado, la sede continúa siendo ocupada por Avencio ${ }^{19}$. Finalmente, en una segunda apelación, el obispo Avencio es despojado de la cátedra astigitana en beneficio de Marciano, pero conserva el grado en sentencia emitida por el concilio de Toledo del año 638, pese a dictarse que había participado en un complot para apartar injustamente de la sede al obispo Marciano ${ }^{20}$. La sentencia es extremadamente dura: Avencio es condenado a penitencia por tiempo indeterminado bajo la vigilancia -sospechamos que nada benigna- de su rival Marciano, y sin embargo no se le priva del grado. Ciertamente los prelados reunidos para dar fin al largo litigio que mantienen Marciano y Avencio parecen más preocupados por salvaguardar la función judicial de los concilios que por reparar las injusticias ${ }^{2 I}$, pero también de hacer lo propio con la dignidad y el honor episcopal. De hecho, en su resolución final añaden que los contendientes no puedan apelar más, a fin de impedir que el escándalo -scandali- continuase en el futuro ${ }^{22}$. La amenaza para quienes lo intentasen no podía ser más determinante: privación de la comunión y deposición de la dignidad ${ }^{23}$.

Los ejemplos se pueden multiplicar. El obispo bracarense Potamio, fornicador confeso, es apartado de la cátedra, que pasa a administrar Fructuoso, por entonces obispo de Dumio. Pero Potamio no pierde la dignidad, salvo por una declaración retórica alusiva a su honor, según el decreto-sentencia emitido en el concilio de Toledo del año $656^{24}$. Con ello se contraviene la tradición de los padres de la Iglesia (los reunidos en el sínodo aluden a ella expresamente) y sobre todo el dictamen claro del concilio de Toledo del año 653, cuando los congregados, ante el conocimiento de un caso innominado, determinan que el obispo que tuviese trato carnal con mujeres sea privado de la cátedra y de la dignidad de su orden -loci

\footnotetext{
18. Vide infra.

19. Iudic. inter Mart. et Avent. epsc., 5 (ed. y trad. MARTín IGLeSIAS, José Carlos: «El ludicium inter Marcianum et Habentium episcopos (a. 638). Estudio, edición y traducción», Habis, 49 (2018), pp. 203-231).

20. Iudic. inter Mart. et Avent. epsc., 43.

21. Stocking, Rachel L.: «Martianus and Isidore: provincial councils in seventh-century Spain», Early Medieval Europe, 6-2 (1997), pp. 169-188.

22. Iudic. inter Mart. et Avent. epsc., 46.

23. Iudic. inter Mart. et Avent. epsc., 45.

24. Decr. pro Potamio epsc. (ed. Martínez Díez, Gonzalo y Rodríguez, Félix: op. cit.). Para lo inusual de la confesión de Potamio y sobre todo para calibrar la vida interna de las iglesias, conviene advertir que los obispos constituidos en tribunal le interrogan sobre si los cargos eran calumniosos, y finalmente si su autoimputación respondía a amenazas y violencias.
} 
et ordinis sui dignitate- ${ }^{25}$. El obispo Eugenio II de Toledo conoce bien la norma aprobada en el concilio del año 653 por haber sido uno de sus promotores, lo que hace destacable la sentencia más medida operada tres años después y redactada con toda probabilidad por el propio Eugenio.

Por su parte, el obispo Gaudencio de Valeria, gravemente enfermo, recibe la penitencia, pero el concilio de Toledo del año 683, haciendo una lectura laxa de toda la normativa canónica hispana, que incapacitaba al penitente, le permite desempeñar sus oficios propios y administrar los sacramentos ${ }^{26}$. En fin, incluso el obispo que no puede ocupar su sede por la oposición de los fieles o por cualquier otro motivo conservaba desde antiguo el honor ${ }^{27}$.

Fuera de determinados pecados, tenidos por especialmente ominosos ${ }^{28}$, únicamente quienes se niegan a ocupar el cargo de forma voluntaria y propician violencias por apetecer una diócesis más rica, y quienes se apropiaran dolosamente del patrimonio eclesiástico, pueden ser depuestos del grado ${ }^{29}$. A decir de Isidoro, al obispo que comete pecados mortales se le suspende o remueve ${ }^{30}$, pero nada indica que sea privado necesariamente de su dignidad. En realidad sólo Valerio del Bierzo parece despreciar el orden episcopal, hasta el extremo de hacer de la muerte del obispo Isidoro de Astorga una suerte de ultio diuina ${ }^{31}$, pero esto solo cabe en la mente de alguien con el carácter del asceta del Bierzo y con tan difíciles relaciones con las jerarquías ${ }^{32}$.

\section{LA INVIOLABILIDAD EPISCOPAL Y LOS DELITOS POLITICOS}

Sin embargo, y es lo que interesa aquí, quienes disfrutan de la dignidad episcopal están excluidos de la muerte violenta..., al menos pública y a mano de los poderes públicos ${ }^{33}$. Ciertamente las fuentes, todas de signo católico, señalan los

25. Conc. VIII Tol., c. 4. No es descartable que esta resolución fuese una advertencia a Potamio y que, al continuar éste con su escandalosa conducta, se llegue a la decisión del año 656. La ley canónica se ve reforzada por una ley general de Recesvinto (L.V. III, 4, 18).

26. Conc. XIII Tolet., c. 10.

27. Conc. I/ Brac., c. 10 (ed. Vives, José: op. cit.). Este concilio bracarense (a. 572) se desarrolló en el Reino Suevo.

28. De ordinario en materia sexual, como ocurre con el obispo cordobés innominado del que Isidoro trata en carta dirigida a Eladio de Toledo, metropolitano de la Cartaginense: Is., Ep. ad. Hell., I (ed. MGHep. III-1; trad. MARTín IGLESIAS, José Carlos, DÍAZ, Pablo C. y VALLEjo GIRVÉs, Margarita: La Hispania tardoantigua y visigoda en las fuentes epistolares. Antología y comentario. Madrid, CSIC, 2020, pp. 571-572). No obstante, también ocurre en otros delitos tenidos como de especial gravedad, como la destrucción de sepulcros por clérigos (Conc. IV Tol., c. 46).

29. Conc. II Brac., c. 12 y 14.

30. Is., Eccl. Off. II, 5 .

31. Val., Ordo quer., 21.

32. Díaz Martínez, Pablo de la Cruz y Fernández Ortiz de Guinea, Lina: «Valerio del Bierzo y la autoridad eclesiástica», Helmantica, 145-146 (1997), pp. 19-35.

33. En el pasado (fines del siglo IV) la intervención del poder público supuso todo un escándalo en el conocido affaire de Prisciliano y sus seguidores, condenados y ajusticiados en Tréveris por el tribunal civil del prefecto del pretorio de las Galias a instancias de un sector del episcopado. Escribano PAÑo, María Victoria: «Haeretici iure damnati: el 
planes funestos de los reyes arrianos o, en su defecto, su maltrato a los obispos católicos ${ }^{34}$. Desde la Galia católica, Gregorio de Tours denuncia cómo el monarca arriano Leovigildo planea el asesinato del obispo Fronimio de Agde, enviándole unos sicarios, y cómo éste únicamente puede salvar la vida huyendo a territorio franco, donde es bienvenido y consagrado como obispo de Vence ${ }^{35}$. También el obispo católico emeritense Masona, a decir del anónimo redactor de su biografía, es amenazado muy seriamente por el rey Leovigildo, incluso con suplicios, según se complace en referir el narrador a fin de igualar a su héroe con los mártires del pasado. Pero su condena final es el destierro ${ }^{36}$. Lo mismo ocurre con Juan de Bíclaro, sospechoso de simpatizar con los orientales. A su vuelta de Bizancio, Leovigildo le destierra a Barcelona, donde permanece durante diez años, hasta la muerte del rey $^{37}$. Solo tras estas peripecias, el de Bíclaro pudo fundar un monasterio y acceder a la cátedra gerundense. En todas estas actuaciones algo parece retener al gran rey arriano, ya sea por razones políticas, por convicciones puramente religiosas o por ambas cosas.

La consideración hacia los obispos se extrema en el Reino de Toledo de signo católico, afectando incluso a los prelados arrianos más irreductibles. La transición hacia la conversión al catolicismo, iniciada por Recaredo en 587 y culminada en el concilio de Toledo en el año 589, produjo tres conspiraciones de signo arriano desarrolladas en otros tantos escenarios: Mérida, Narbona y Toledo ${ }^{8}$. En ellas se advierte el respeto a la inviolabilidad de los obispos, aún de los arrianos.

A comienzos del reinado Recaredo, en Mérida, los arrianos Segga y Sunna, éste obispo de la ciudad, traman el asesinato del obispo católico Masona. Solo con la protección de Claudio y -prodigium mediante- la traición de Witerico, se puede evitar tal desafuero. Mientras a Segga le amputan la mano y se le recluye en la Gallaecia $^{39}$, Sunna parte al exilio, sin que tengamos noticias de violencia alguna

proceso de Tréveris contra los priscilianistas (385)», en Cristianesimo e specifità regionali nel Mediterraneo latino (sec. IV-VI). XXII Incontro di studiosi dell'Antichità cristiana. Roma, Institutum Patristicum Augustinianum, 1994, pp. $393-416$.

34. Igualmente, estas mismas fuentes suelen recoger la muerte execrable de los obispos de la secta, siguiendo con ello una norma propia del género hagiográfico.

35. Greg. Tur., H.F.. IX, 24.

36. VSPE V, VI, 81-110. Este exilo o destierro de los obispos, en su calidad de líderes ciudadanos, contaba con precedentes en la Hispania de los regna germánicos. En fechas tan tempranas como el año 411, el obispo Sabino de Sevilla fue depuesto por los suevos y un grupo de eclesiásticos hispalenses, teniendo que partir al exilio galo. No regresó del destierro hasta la llegada de los visigodos a la ciudad en 457-458: Hyd., Chron., 124 y $192^{a}$ (ed. y trad. TRANOY, Alain: SC 218). Pero, incluso en época de anarquía y guerra, escandalizaba el maltrato o la muerte dada a obispos $u$ otras gentes de religión, proceder de marginales como los bagaudas encabezados por Basilio, que hirieron de muerte al obispo León (Hyd., Chron., 141). Más escandaloso aún fue la actuación de los godos al mando de Teodorico, aliado de Roma pero hereje, pues maltrató a vírgenes y clérigos en Braga, y apresó a dos obispos y sus clérigos en Astorga (Hyd., Chron., 174 y 186). El narrador de estos episodios, el obispo Hidacio de Chaves, también fue objeto durante tres meses de una «miserable cautividad» (Hyd., Chron., 201 y 207).

37. Is., Vir. II., 31.

38. Collins, Roger: «¿Dónde estaban los arrianos en el año 589?», en Concilio III de Toledo. XIV Centenario (5891989). Toledo, Arzobispado de Toledo, 1991, pp. 211-222.

39. Ioan. Bicl., Chron. a. 588. 1 (ed. CAmpos, Julio: Juan de Biclaro, obispo de Gerona. Su vida y su obra. Introducción, texto crítico y comentarios. Madrid, CSIC, 1960). 
contra él fuera del extrañamiento. Acaba sus días, con cierto éxito, en el exilio mauritano, aunque, para seguir las normas hagiográficas, el narrador añada que allí tiene un pésimo fin ${ }^{40}$. La más benigna condena de Sunna responde a su condición de obispo, aunque lo sea de la secta. El respeto por la dignidad episcopal es tal que incluso este «pseudo-obispo», de haberse convertido, habría recibido una nueva silla catedralicia en otra sede distinta a la emeritense ${ }^{41}$. Por tanto, la rebelión de Mérida, para cuya resolución fue vital la traición del futuro rey Witerico, termina con dos penas muy distintas, pues mientras Segga es confinado en la Gallaecia después de amputarle las manos, el obispo arriano Sunna, verdadera cabeza del complot a decir del anónimo biógrafo emeritense, se le ofrece la oportunidad de convertirse al catolicismo y, tras la debida penitencia, recibir otra cátedra. Solo ante su contumaz negativa, se ve obligado a la expatriación. Finalmente, los restantes confabulados son condenados a la pérdida de sus patrimonios y honores, exiliados y confinados. Como quiera que el noble godo y comes ciuitatis Vagrila, que había atentado infructuosamente contra el obispo Masona, se refugia en la basílica de Santa Eulalia, Recaredo le condena a la servidumbre de la mencionada iglesia, a él y a su familia, si bien Masona le concede finalmente la libertad ${ }^{42}$. Es evidente que las penas impuestas dependían del protagonismo tenido en la conspiración, pero también de la condición de los participantes. El diferente trato penal pro qualitate personarum es una constante, $\mathrm{y}$ al respecto destaca la relativa benignidad del trato dispensado al obispo arriano Sunna.

En el año 589, y cuando la conversión del Reino ya era inminente, el obispo arriano Uldila, con toda probabilidad de Toledo, participa junto a la irreductible reina arriana Gosvinta en un complot contra Recaredo. Uldila, que suma al delito de conspiración el de sacrilegio al haber arrojado al fuego unas sagradas formas, es condenado a destierro; la reina madre -casualmente- termina sus días en este tiempo, según añade el biclarense ${ }^{43}$. Una vez más, la pena impuesta a un obispo, en este caso muy próximo a los círculos del poder y por tanto con una actuación de gravedad, y quizás especialmente dolorosa por cercana para el monarca, no supone la pérdida de la vida. Uldila no es ajusticiado.

Peor suerte corre el también obispo arriano Ataloco de Narbona, cómplice junto con los condes Granista y Vildigerno en una rebelión secesionista en connivencia con los francos, $y$, de ser posible, con el objetivo último de arrebatar el Reino a Recadero. Si damos crédito a la narración de Gregorio de Tours, los obispos de la secta no podían sino sentirse agraviados, pues Recaredo les acusaba de no propiciar prodigios y milagros, a diferencia de lo que hacían los obispos

40. VSPE V, XI, 70-81. VALLEjo GIRVÉs, Margarita: «¿El éxito de un desterrado arriano?: la evangelización del obispo Sunna en Mauritania», en González SALINERO, Raúl: Marginados sociales y religiosos en la Hispania tardorromana y visgoda. Madrid, Signifer Libros, 2013, pp. 171-191.

41. VSPE V, XI, 53-61.

42. VSPE V, XI, 86-114.

43. Ioan. Bicl., Chron. a. $589,1$. 
católicos, prueba de la verdad de la doctrina de estos últimos. Como quiera que el rey manda enviados a la Narbonense para lograr la conversión del pueblo de esta provincia al catolicismo, Ataloco y los mencionados condes se sublevan. Finalmente los sublevados son derrotados por el dux Claudio, y Ataloco fallece algo después -acaso suicidándose- en la cama de su celda ${ }^{44}$. Funesta pero oportuna resolución que evita la actuación del muy católico rey Recaredo. El crimen del obispo arriano había sido especialmente execrable, pues en el fragor de la rebelión habían muerto clérigos y otros muchos católicos ${ }^{45}$.

Tras la aún cercana guerra civil protagonizada por Hermenegildo y las sublevaciones anteriormente descritas, que habían debido exacerbar los ánimos, el concilio de Toledo del año 589, impulsado por Recaredo, supone un pacto balsámico entre la Iglesia católica y la nobleza goda, encabezada por el monarca, respetuoso con los obispos provenientes de la iglesia gótico-arriana. La prueba más evidente es la existencia, contra toda la tradición canónica sobre la naturaleza monárquica del episcopado, de dos obispos en una misma diócesis, fruto de la consideración a la dignidad de los procedentes de la fe arriana. Es el caso de la ciudad de Elvira. Allí coexisten los obispos Esteban y Pedro. Del primero sabemos por su participación en el sínodo toledano y en el concilio provincial de Sevilla del año 590. Además contamos con una inscripción funeraria hallada en Valderrubio, a seis kilómetros de llurco (Cerro de los Infantes, Pinos Puente, Granada), que usa como datación la indicación del primer año del obispado de Esteban. Respeto de Pedro, suscribe igualmente los mencionados concilios de Toledo y de Sevilla. En el concilio hispalense, Esteban precede a Pedro, por lo que su condición episcopal sería anterior. No falta quien entiende que este último, Pedro, es el antiguo obispo arriano de la población. En todo caso, tras el concilio de Toledo y al menos hasta el de Sevilla, por unos años, la diócesis iliberritana cuenta con dos obispos católicos ${ }^{46}$.

En medio de la precariedad propia del cambio de régimen que supone la confesionalidad católica del Reino implantada por Recaredo, Juan de Bíclaro se complace en relatar cómo tras la celebración solemne del concilio de Toledo del año 589, al año siguiente, el monarca actúa con decisión ante quienes atentan contra su persona y aspiran a la tiranía. En Toledo el dux prouinciae y cubicularius Argimundo conspira contra el rey. Descubierto, Argimundo es condenado a decalvación y amputación de la mano derecha, mientras sus cómplices, confesos, son ajusticiados ${ }^{47}$. Nada dice Juan de la más que probable implicación de medios

44. Gerg. Tur, L.H. IX, 15 .

45. VSPE V, XII, 1-24.

46. Conc. III Tol., susbcr.; Conc. I Hisp., susbcr. (el códice Vigiliano modifica la suscripción de Pedro en el concilio I de Sevilla, haciéndole erróneamente obispo de Guadix); PASTOR MUÑoz, Mauricio, CILA IV: Granada. Sevilla, Junta de Andalucía, 2002, n 96 (llama la atención sobre la inusual datación por el año del obispado de Esteban). GARCíA Moreno, Luis Agustín: Prosopografía del Reino Visigodo..., n² 218, estima que Pedro pudo ser el obispo iliberitano procedente del arrianismo.

47. Ion. Bicl, Chron. a. 590, 3. Castillo Lozano, José Ángel y Molina Gómez, José Antonio, «El castigo aplicado al Tyrannus Argimundo según el Chronicon de Juan de Bíclaro», Potestas, 9 (2106), pp. 35-52. 
eclesiásticos de origen arriano. De haber participado éstos en el complot, se estaría ante una omisión claramente intencionada del biclarense, destinada a tranquilizar a los más renuentes y acaso a congraciarse con ellos mediante el silencio.

La conversión, establecida en términos transaccionales, produjo un optimismo tan comprensible como ingenuo. El entusiasta dictamen del concilio de Narbona del año 589 declara que ningún clérigo debe participar en conspiraciones ni en rebeliones. Para ello se aduce nada menos que el concilio de los concilios, esto es, el sínodo universal de Nicea ${ }^{48}$. El siglo VII se encargará de demostrar que se trata de un mero desiderátum ${ }^{49}$.

De hacer caso a nuestras interesadas fuentes, pareciera que sólo los adversarios del Reino, aunque estos profesen la fe católica, pueden caer en el execrable crimen que supone atentar contra la vida de un obispo. Isidoro no duda en recordar cómo, según se dice -dicitur-, el obispo Liciniano de Cartagena fue envenenado en Constantinopla, y ello ab aemulis ${ }^{5}$. Al fin y al cabo, los orientales eran sospechosos de heterodoxia para los hispano-católicos, y acaso, por razones familiares, especialmente odiosos para el prelado sevillano.

Durante el reinado de Witerico, los obispos Ilergio de Egara, Sergio (que llegaría a ser obispo metropolitano de Narbona) y un tal Agapio, de sede desconocida, prestan ayuda al conde Búlgar, entonces perseguido por el rey ${ }^{5 \mathrm{I}}$. De sus precedentes conspiradores, cabría esperar que el rey Witerico no tuviera en consideración cuestiones de naturaleza religiosa para sus actuaciones. Sin embargo, no sabemos de represalia alguna sobre estos personajes, y el argumento ex silentio parece definitivo. Al contrario, es posible que la mediación de estos obispos favoreciera a Búlgar, pues sabemos que Witerico finalmente puso en libertad al conde.

El escándalo que supone la muerte violenta de un prelado es tal que el monarca Sisebuto aprovecha la ocasión para redactar una auténtica passio con motivo del asesinato del obispo Desiderio, haciendo del mismo un mártir de sangre. Con ello conseguía estigmatizar a los enemigos del Reino a la par que hacer un guiño, una aproximación diplomática, al triunfante rey merovingio Clotario $\mathrm{I}^{52}$. Como ocurría con los perseguidores y gobernadores del pasado romano, Sisebuto no da a los verdugos, Teodorico Il y Brunequilda, la satisfacción de haber acabado

48. Conc. Narb., c. 5 (ed. Vives, José: op. cit.).

49. Lo cierto es que los obispos participaron en toda suerte de conspiraciones contra la corona y el Reino. Además de los metropolitanos de la capital regia, los obispos cuyas diócesis se situaban en las fronteras del Reino tenían una posición privilegiada para estas intentonas. El concilio de Toledo del año 633, bajo el rey Sisenando, les prohíbe expresamente tener relaciones con los enemigos de fuera de las fronteras (Conc. IV Tol., c. 30). El asunto era bien conocido por Sisenando, pues él mismo contó con apoyo exterior para la deposición del rey Suintila.

50. Is., Vir. II., 29 (ed. Codoñer Merino, Carmen: El De Viris Illustribus de Isidoro de Sevilla. Estudio y edición crítica. Salamanca, Universidad de Salamanca-CSIC, 1964). En este contexto aemuli son los contrarios, quizás eclesiásticos. EI hecho se ha interpretado como un asesinato llevado a cabo por quienes tenían a Liciniano como poco leal al Imperio.

51. Epist. Wisigot. 13 (ed. GIL, Juan: Miscellanea Wisigothica. Sevilla, Universidad de Sevilla, ${ }^{2} 1991$; trad. MarTín Iglesias, José Carlos, Díaz, Pablo C. y Vallejo GiRvés, Margarita: op. cit., pp. 507-511).

52. Fontaine, Jacques: «King Sisebut's Vita Desiderii and the Political Function of Visigothic Hagiography», en JAMES, Edward: Visigothic Spain: New Approaches. Oxford, Clarendon Press, 1980, pp. 93-129. 
impunemente con un obispo católico, pues, a su decir, Desiderio termina sus días por propia mano, golpeándose la cabeza con un bastón ${ }^{53}$.

En el reinado de Suintila, tiene lugar la referida deposición del obispo Marciano de Écija, dando comienzo al pleito entre éste y su sucesor en la cátedra, el obispo Avencio. Una de las acusaciones contra Marciano es hablar contra el rey y consultar a adivinos sobre su muerte ${ }^{54}$. De ser cierto, estaríamos ante la manifestación del descontento de un sector eclesiástico y nobiliario con el monarca ${ }^{55}$. Con independencia de que se trate de una acusación justa o difamatoria, lo relevante a nuestros efectos es que Marciano es depuesto y despojado de toda dignidad -omni dignitate priuatum- y honor-deiectonem honoris- por un concilio provincial habido en los años 628 o 629 (del que no extraña que desaparecieran sus actas), permaneciendo un año preso, hasta el derrocamiento del rey Suintila ${ }^{56}$. Es posible que esta privación de la dignidad, a mi parecer excepcional a luz de la casuística aquí expuesta, deba ser entendida por la participación de Isidoro en la sentencia, sin duda muy exigente sobre la calidad del episcopado y acaso sin que estén ausentes consideraciones de orden político. Sin embargo, fuera de la violencia que supone un año de encarcelamiento, no se atenta contra la vida de Marciano, pese a la grave acusación de conspiración contra el monarca reinante.

Como se expuso anteriormente, un monarca que destaca por su gobierno enérgico como Chindasvinto, no duda en legislar contra los conspiradores. La pena para estos delitos -scelera- de especial gravedad es la muerte o, en su defecto, azotes, decalvación, reducción a servidumbre, exilio e incautación de bienes ${ }^{57}$. Sin embargo, Chindasvinto se contenta con la degradación, deposición, penitencia y excomunión hasta el último día de la vida de todo clérigo que participe en estos mismos actos, según el dictamen del concilio VIl de Toledo ${ }^{5}$. Ciertamente es una pena canónica de extraordinaria dureza, pero menor que la destinada a los laicos. El asunto es tanto más notable si tenemos en cuenta que, según declaran los padres sinodales, el crimen de apoyar a quienes aspiran a la tiranía o de los

53. Sis. Reg., Vit. Desid., 18 (ed. Martín Iglesias, José Carlos: «Une nouvelle edition de la Vita Desiderii de Sísebut, acompagnée de quelques réflexions concernant la date des Sentetiae et du De viris illustribus d'Isidore de Séville», Hagiographica, 7 (2000), pp. 127-180; trad. DíAz y DíAZ, Pedro R.: «Tres biografías latino medievales de San Desiderio de Viena (traducción y notas)», Fortunatae, 5 (1993), pp. 215-252).

54. ludic. inter Mart. et Avent. epsc., 27-30. Díaz MARTínez, Pablo C.: «Quam ille de vita regis [...] consuluisset. Adivinación y violencia política en la Hispania visigoda», en Montero Herrero, Santiago y Perea Yébenes, Sabino: Adivinación y violencia en el mundo romano, Salamanca, Universidad de Salamanca, 2020, pp. 271-292

55. García Moreno, Luis Agustín: Historia de España Visigoda. Madrid, Cátedra, 1989, p. 155 e ldem, «La oposición a Suintila: Iglesia, Monarquía y Nobleza en el Reino Visigodo», Polis, 3 (1991), pp. 21-22. En otro lugar se analizó este hecho como una querella interna de la iglesia astigitana: CASTILLO MALDONADO, Pedro: «In ecclesia contra ecclesiam: algunos ejemplos de disputas, violencias y facciones clericales en las iglesias tardoantiguas hispanas», Antiquité Tardive, 15 (2007), pp. 272-276.

56. Iudic. inter Mart. et Avent. epsc., 6 y 9.

57. L.V. II, $1,8$.

58. Conc. VII Tol., c. 1. Obviamente un juicio eclesiástico no podía establecer una condena de sangre. La mera existencia de la norma, con valor de ley, recordaba la prohibición de ajusticiar a los clérigos. 
desertores que se pasan al enemigo es tanto más horrible al participar eclesiásticos que cuando lo hacen los laicos.

Esta diferente consideración y trato de eclesiásticos y laicos se evidencia cuando el peligro se materializa, es decir, cuando se producen efectivamente secesiones, desórdenes y rebeliones contra el poder establecido. Al poco de su elección y unción como rey, Wamba tiene que hacer frente a una secesión en la Narbonense. Comienza en la primavera del año 673, en torno a la ciudad de Nîmes, encabezada por el comes de la ciudad Ilderico, el obispo Gumildo de Magalona y Ramiro, abad de un monasterio tal vez cercano a Nîmes. Desde la óptica militar, no parece que pudiese alarmar en exceso al monarca, ocupado en una expedición contra los vascones, pero todo va a cambiar cuando el enviado para sofocarla, el dux Paulo, se confabula con los sublevados. Con Paulo la revuelta se extiende a parte de la Tarraconense y a toda la Septimania, además de incrementar sus huestes con mercenarios francos y vascones transpirenaicos. Finalmente se hace nombrar rey en Narbona ${ }^{59}$. A la vista del cariz de los acontecimientos, Wamba decide intervenir con decisión. Restablece la situación en la Tarraconense, atraviesa los Pirineos y emprende la ofensiva sobre las ciudades galas rebeldes. En septiembre del mismo año, la situación se ha restablecido ${ }^{60}$.

En todo este episodio, relatado prolijamente por Julián de Toledo siguiendo las normas de la historiografía clásica ${ }^{6}$, contamos con la participación de obispos, ya sea de parte de los sublevados o, como es el caso del obispo Aregio de Nîmes, de Wamba. Aregio se opone a los sublevados capitaneados por Ilderico. Es depuesto de su cátedra y sustituido por Ramiro, que de esta manera recibe el premio de su conjura, siendo ordenado irregularmente con el concurso de dos obispos extranjeros. Por tanto Aregio es privado de su dignidad y sede -ordinis et loci dignitate pribatum-, y enviado encadenado al país de los francos ${ }^{62}$; vejado, apresado y exiliado, pero no ajusticiado.

Paulo, antes de hacer públicas sus aspiraciones tiránicas, consigue la adhesión de Ranosindo, dux de la Tarraconense, y del gardingo Hildigiso. La participación de Ranosindo, que insta a Paulo para que se alce como rey, significa la adhesión

59. Si damos crédito a una Epistola Pauli perfidi (ed. Levinson, Wilhelm: CCSL 115; trad. Díaz y Díaz, Pedro Rafael: «Julián de Toledo: Historia del rey Wamba (traducción y notas)», Florentia lliberritana, 1 (1990), pp. 84-114), transmitida en la tradición codicológica junto a la Historia Wambae de Julián de Toledo, pudiera entenderse que el rebelde intenta un acuerdo frustrado con el rey: la división del Reino (Este, para sí mismo, y Austral, para Wamba). Sin embargo, el tono del escrito es ciertamente provocativo, tal como señalan Martín IgLeSIAS, José Carlos, Díaz, Pablo C. y VaLLejo GIRVÉS, Margarita: op. cit., pp. 758-759.

60. Para los aspectos militares, IsLA FrEZ, Amancio: Ejército, sociedad y política en la Península lbérica entre los siglos VIl y XI, Madrid, 2010, pp. 25-44; PARRA Romo, Ángela, «El ejército visigodo en campaña y la secesión de la Narbonense», Studia Historica. Historia Antigua, 36 (2018), pp. 221-251.

61. Salvador Ventura, Francisco: «La Historia Wambae de Julián de Toledo y sus caracteres de historiografía clásica», Habis, 50 (2019), pp. 391-407.

62. Iul., H.W., 6 (ed. CCSL 115; trad. Díaz y Díaz, Pedro Rafael: art. cit.). García Moreno, Luis Agustín, Prosopografía del Reino Visigodo..., $\mathrm{n}^{\circ} 559$, cree que tras el fracaso de la rebelión sería repuesto en su obispado, corrigiendo para ello la suscripción presente en el concilio de Toledo del año 683 (Conc. XIII Tol., subscrip.: «lohannes abba Regineum Aucensis episcopi similiter»: ed. Martínez Díez, Gonzalo y Rodríguez, Félix: op. cit., vol. VI. Madrid, CSIC, 2002, p. 263 y n. 26). 
de Barcelona y Gerona, aunque no de la capital provincial, Tarragona, que permanece fiel a Wamba. Julián nada dice al respecto, pero es de creer que el obispo tarraconense, tal vez Cipriano ${ }^{63}$, no fue atraído por el cambio de fidelidades experimentado por el duque provincial, o al menos supo nadar y guardar la ropa. Por su parte, el obispo de Gerona, Amador, participa en la sublevación. Es muy posible que tuviera un alto grado de implicación, pues del martyriumbasilica del mártir Félix procede la corona usada por el tirano Paulo. No obstante, nada sabemos de su destino al caer la ciudad en manos de las tropas reales ${ }^{64}$. Tampoco se pronuncia Julián sobre el obispo de Barcelona. Explica cómo allí es apresado el rebelde Pompedio junto con otros, entre ellos el diácono Hunulfo, pero calla sobre el obispado de la ciudad ${ }^{65}$. Aunque Julián tiende a minimizar la participación de los eclesiásticos en la sublevación, caso de Amador (y sobre todo a enfatizar la actuación de quienes se mantienen fieles a Wamba, como Aregio), la cátedra de Barcelona pudiera estar vacante ${ }^{66}$.

No es fácil la situación de los partidarios de la rebelión ante el avance de las tropas de Wamba y su incursión en la Galia. Ranosindo e Hildigiso, que han acudido a la defensa de las Clausurae pirenaicas, son vencidos y conducidos con las manos atadas a la espalda -deuictis post tergum manibus- ante el rey ${ }^{67}$. El obispo Jacinto (de sede desconocida) defiende el castro de Llivia, donde cae prisionero $^{68}$. En Narbona es apresado el primicerio Gultricián ${ }^{69}$. El dux Witimiro, huido de Cerdane, se refugia en la iglesia de Santa María de la capital, donde finalmente es apresado, tratado de mala manera -uiliter tractus-, encadenado y azotado junto con sus secuaces ${ }^{70}$. Wamba también somete a las ciudades de Béziers y Adge, pero Julián, una vez más, nada dice de la participación o no de sus obispos en la revuelta. Sí conocemos que el falso obispo - pseudoepiscopumRamiro, que ha huido de Narbona, se refugia en la primera, donde es capturado; y en la segunda se apresa al obispo Wilesindo (quizás el titular de cátedra de la ciudad) y a su hermano Ranosindo ${ }^{75}$.

Pero es en Nîmes donde se decide la suerte última de la rebelión. Argebado, metropolitano de la Narbonense, se ha opuesto a la conjura alentada por

\footnotetext{
63. Ausente la cátedra de Tarragona en el concilio XII de Toledo (a. 681), al XIII de Toledo (a. 683) asiste el arcediano Espasando en representación del obispo Cipriano.

64. Iul., H.W., 11 y 26.

65. Iul., H.W., 11; ludic. in tyrann., 3 (ed. CCSL 115; trad. Díaz y Díaz, Pedro Rafael: art. cit.)

66. No creo que pudiera serlo Idalio (amigo y correspondiente de los obispos Julián de Toledo y Suneifredo de Narbona: Martín Iglesias, José Carlos, Díaz, Pablo C. y Vallejo Girvés, Margarita: op. cit., pp. 742-756), obispo de Barcelona representado por el diácono Laulfo en el concilio de Toledo del año 683: la Historia Wambae nada dice de la cátedra de Barcelona. No obstante, el que la sede esté representada en el mencionado sínodo toledano únicamente por un diácono pudiera hacer sospechar de una cierta ambigüedad de Idalio en la sublevación, recompensada con el silencio de Julián.

67. Iul., H.W., 11.

68. Iudic. in tyrann., 3.

69. Iudic. in tyrann., 3 .

70. Iul., H.W., 11-12.

71. Iudic. in tyrann.. 3
} 
Ilderico. Además, enterado de los planes de Paulo, se resiste a participar en la sublevación. No obstante, de mejor o peor grado, acaba por sumarse al bastión rebelde en Nîmes. Ante la inminente entrada del ejército de Wamba en la ciudad, el obispo se adelanta para recibir al rey, se postra ante él y suplica el perdón para los rebeldes. Julián ensalza la actitud del muy sagrado príncipe -sacratissime princeps-, Wamba, pues manda al obispo alzarse de la tierra y le comunica su decisión de no ajusticiar a los rebeldes, aunque sin que por ello salieran impunes. Sin embargo, ante la insistencia «negociadora» del obispo, el rey se encoleriza y le promete respetar íntegramente su vida, pero sin dar garantías para el resto de rebeldes ${ }^{72}$. Debemos pues entender que Wamba librera al obispo Agrebado de toda pena, acaso en consideración a las presiones recibidas al comienzo de la rebelión, algo no extensible a los acantonados en la ciudad, que finalmente son hechos prisioneros con un futuro inmediato nada halagüeño. Entre los eclesiásticos apresados entonces, destaca el obispo Gumildo de Magalona. Éste se ha adherido a la sublevación desde sus comienzos, si no la ha propiciado, y posteriormente a los partidarios de Paulo. Cuando las tropas de Wamba avanzan hacia su ciudad de Magalona, huye a Nîmes, donde cae apresado ${ }^{73}$. Por su parte, el tirano Paulo es sacado de su refugio en el anfiteatro de la ciudad, apresado y maltratado -uiliter contrectatur-74. Julián incide en la humillación de Paulo y sus secuaces: «Paulo cargado de hierros junto a los demás, es presentado al soberano, sentado en su trono. Entonces, según la antigua costumbre, inclina el cuello, doblando la espina dorsal ante las reales plantas»; así como en la misericordia del monarca: aunque merecedores de la muerte por sus delitos, son decalvados (una pena tan infamante como peligrosa $)^{75}$. Por lo que respeta a los francos participantes en la rebelión, Wamba respeta su vida, de modo que unos permanecen como rehenes y otros son liberados tras unos días ${ }^{7}$. Finalmente los apresados son conducidos a Toledo y allí exhibidos en escarnio: con sus cabezas afeitadas, la barba rala, los pies descalzos, vestidos con túnicas y sayones sucios, montados sobre carros llevados por camellos y encabezados en esta humillante procesión por Paulo coronado con una banda de cuero negro ${ }^{77}$.

Un documento tal vez redactado en Nimês en 673 antes de dictarse la sentencia final por el rey y acaso utilizado por Julián para componer su narración de los acontecimientos $^{78}$, relata con detalle quiénes son los capturados en Nîmes: además

72. Iul., H.W., 7 y 21-22.

73. lul., H.W., 13 .

74. lul., H.W., 24

75. Iul., H.W., 27. Sobre la pena de decaluatio, $\mathrm{CrOuCH}$, Jace, «The Judicial Punishment of Decalvatio in Visigothic Spain: a Proposed Solution based on Isidore of Seville and the Lex Visigothorum», The Mediterranean Review, 3-1 (2010), pp. $59-77$

76. lul., H.W. 25. Es una misericordia regia que contrasta con los planes de los rebeldes, que se habían juramentado para no perdonar la vida de Wamba y los suyos (lul., H.W.,14; lud. in tyrann., 6)

77. lul., H.W., 30

78. Thompson, Edward A.: Los godos en España. Madrid, Alianza, ${ }^{2} 1979$, p. 250; MARTín, José Carlos: «Julián de 
de Paulo y sus secuaces laicos, incluida una multitud de francos, el obispo Gumildo y los clérigos Frugisclo, Flodario, Wistrimiro, Ranemundo, Andosindo, Adulfo, Máximo y Juan ${ }^{79}$. A decir del mencionado documento, Paulo y sus cómplices son sometidos a juicio por el rey ante los gardingos, oficiales de palacio y el ejército en su totalidad, en una auténtica asamblea ${ }^{80}$. La acusación es de traición con el concurso de gentes extranjeras, atentar contra la vida del rey y promover las discordias en el Reino, y ante todo de haber roto el juramento divino -sub diuni- de fidelidad a Wamba que en su día ellos mismos firmaron por propia mano, en prueba-formulario legal que se les presenta en el juicio ${ }^{81}$. En fin, su delito no es otro que el de intentar arrebatar el Reino contra el designio divino - contra Dei uoluntatem- ${ }^{82}$. Declarados culpables, para la sentencia se aduce lo dictado en el concilio de Toledo del año 633 en su canon 75, y en la ley civil II.I.6, revisada por Recesvinto en el Liber Iudicorum. Además de la privación de la facultad de testificar, la pena es pecuniaria, con la pérdida de sus bienes y los de sus descendientes en beneficio de Wamba, que puede distribuirlos a placer entre sus fideles, y también física, con la pena de muerte. No obstante, a quienes el rey concediese seguir vivos, debían serles enucleados los ojos ${ }^{83}$.

Sin embargo, hay que tener en cuenta que la situación era extrema, tanto por la presión exterior como por la profunda tensión y división entre las principales familias del Reino ${ }^{84}$. Solo con esta consideración se comprende que, tras ser condenados como traidores por Wamba, en el concilio de Toledo del año 683 hasta quienes participaron abiertamente o de grado en la intentona secesionista y tiránica son finalmente indultados unos años después, obteniendo el perdón a petición del rey Ervigio $^{85}$. No obstante, lo cierto es que el rastro de los antiguos rebeldes, incluidos

Toledo», en CODOÑER, Carmen: La Hispania visigótica y mozárabe: dos épocas en su literatura. Salamanca, Ediciones Universidad de Salamanca, 2010, p. 161.

79. Iudic. in tyrann., 4. Extraña la ausencia de mención alguna de llderico en esta relación, como advierte GARCíA Herrero, Gregorio: «Sobre la autoría de la Insultatio y la fecha de la composición de la Historia Wambae de Julián de Toledo», en Los visigodos y su mundo. Madrid, Comunidad de Madrid, 1991, p. 197.

80. No obstante, el derecho visigodo es un derecho del rey en exclusiva: PETIT, Carlos: «Crimen y castigo en el Reino Visigodo de Toledo», en Los visigodos y su mundo. Madrid, Comunidad de Madrid, 1991, p. 218. Por ello el monarca es el único que puede indultar, algo que ratifica el concilio de Toledo del año 681, reunido bajo el rey Ervigio (Conc. XII Tol., c. 3).

81. Iudic. in tyrann., 1 y 6

82. ludic. in tyrann., 2 .

83. Iud. in tyrann., 1 y 7. Pena de enucleación que no se cumplió o que Julián se encarga de dulcificar (lul., H.W., 27)

84. Al respecto, García Moreno, Luis Agustín: Historia de España..., pp. 172-173.

85. Conc. XIII Tol., tomus y c. 1. Precisamente, la sucesión Wamba por Ervigio no está exenta de sospechas. Ante lo que parecía su inminente muerte, Wamba es tonsurado y recibe el hábito religioso. Restablecido, no podía volver a ocupar el trono, por lo que es recluido en un monasterio y le sucede Ervigio. Los reunidos en el concilio XII de Toledo tratan el que, en sus palabras, era el asunto más urgente: según manifiestan los padres sinodales, el propio Wamba había dispuesto su sucesión en la persona de Ervigio, que inmediatamente es ungido por el obispo Julián de Toledo, todo ello examinado por el conjunto de los reunidos mediante la debida documentación escrita. Sin embargo, resulta sospechoso que los obispos se declaren solidarios con esta consagración y en consecuencia se liberen del juramento de fidelidad prestado al anterior rey. Se resolvía así una crisis fruto de una desgraciada circunstancia, o bien de un golpe de estado que contó con el apoyo de Julián de Toledo. Sea de una forma u otra, en contrapartida el concilio fija un habeas corpus (quizás sería mejor hablar de privilegios) que protegía, entre otros, a los obispos (Conc XIII Tol., c. 2). Una valoración en Díaz Martínez, Pablo C.: «Concilios y obispos en la Península Ibérica (siglos VI-VIII)», en Chiese locali e chiese regionale nell'Alto Medievo, Spoleto, Centro Italiano di Studi Sull'Alto Medievo, 2014, pp. 143-1144. En este episodio se mezclan 
los eclesiásticos, se difumina en las sombras, nada sabemos en adelante de ellos, y sobre la Narbonense pesan acusaciones de traición que parecen afectar también a sus obispados ${ }^{86}$.

En las postrimerías del Reino, el obispo Sisiberto de Toledo trama una conjura contra el rey Egica ${ }^{87}$. Podemos sospechar que las relaciones entre el monarca y un sector de la nobleza, incluida una parte del obispado, eran tensas. En todo caso, descubierto Sisiberto, es privado de su sede, honor y bienes, excomulgado y encarcelado de por vida, pero no ajusticiado. A petición del rey Egica, Sisiberto es juzgado ante los obispos convocados al Concilio de Toledo del año 693. Reunidos con tal fin, los obispos dictaminan que sea condenado a exilio perpetuo, excomulgado hasta el final de sus días y sus bienes confiscados, además de privado del orden y honor del episcopado ${ }^{88}$. El juicio precede a la apertura de la reunión sinodal, y con él se sigue un privilegio eclesiástico, esto es, que los obispos sean juzgados por los iguales. Asimismo, un juicio eclesiástico tiene una consecuencia trascendental: la imposibilidad de aplicar la pena capital. Sisiberto no estaba solo, pues sabemos que el monarca aprovechó para hacer una purga, con los correspondientes destierros y confiscaciones de bienes ${ }^{89}$. El propio concilio establece que este sea el proceder en el futuro para quienes conspiraren contra el rey, pudiendo únicamente el monarca conceder el perdón. Debe entenderse que esta disposición es fruto de un consenso entre los allí reunidos, dos tercios del conjunto del obispado visigótico, y la propia corona; o acaso más bien de una imposición del monarca. Finalmente, al ser depuesto de la cátedra el obispo Sisberto se produce toda una reestructuración del mapa catedralicio que es muy significativa: el obispo hispalense Félix ocupa la sede de Toledo; Faustino, hasta entonces obispo de Braga, ocupa la vacante hispalense del anterior; y en la cátedra bracarense se emplea otro Félix. Se trata de auténticas promociones en lo que pudiéramos llamar el cursus episcoporum, pero sobre todo

noticias sobre un supuesto envenenamiento de Wamba, que han merecido distinto crédito entre la bibliografía: cf. TEILLET, Suzanne, «La déposition de Wamba. Un coup d'état au VII siècle», en Holtz, Louis y FredouILLe, Jean-Claude: De Tertullien aux Mozarabes. Mélanges offerts à Jacques Fontaine, t. II. Paris, Études Augustiniennes, 1992, pp. 99-113; y BRONISCH, Alexander Pierre, «Precisiones sobre algunas informaciones históricas en la Crónica de Alfonso III», Edad Media. Revista de Historia, 12 (2011), pp. 37-41.

86. Como demuestra la extremada dureza de la Insultatio uilis storici in tyannidem Galliae. Por lo que respecta a los obispados de la provincia, Narbona, Carcasona y Lodève acuden al concilio de Toledo del año 683, pero por representación (como ocurre también con los obispados de la Tarraconense que habían participado en la rebelión, Gerona y, acaso, Barcelona). Sí asisten los obispos de Béziers y de Magalona. Del obispado de Nîmes nada se sabe desde la rebelión de Paulo. En fin, sólo el obispado de Béziers repetirá asistencia en posteriores sínodos toledanos.

87. VAlverde CASTRO, Rosario: Los viajes de los reyes visigodos de Toledo (531-711). Madrid, La Ergástula, 2017, pp. 131-137.

88. Conc. XVI Tol., C. 9 y Decr. iudicii.

89. El reinado de Egica se caracteriza por toda una política purgas, confiscaciones y exilios, aunque finalmente los afectados obtuvieron el perdón del rey Witiza (Chron. a. 754, V, 41 y VI, 44). Sobre el alcance de la conjura de Siseberto da una idea la calidad de los implicados, entre ellos la antigua reina Liuvigoto, viuda de Ervigio y madre de Cixilona, la esposa del propio Egica (Conc. XVI Tol., c. 9). Véase distinta lectura en THOMPSON, Edward A.: op. cit., p. 278 y MARTIN, Céline: La géographie du pouvoir dans l'Espagne visigothique. Villenueve d'Ascq, Press Universitaires du Septentrion 2003, p. 197, para quienes los conjurados planeaban atentar contra Liuvigoto y otros fideles regis. 
es toda una manifestación de cesaropapismo ${ }^{90}$, esto es, del poder del rey sobre la Iglesia por la consideración teocrática de la corona.

\section{CONCLUSIONES}

En lo que respecta a la corona, los obispos incumplieron reiteradamente el deber de custodiar la ley, y la incumplieron ellos mismos ${ }^{91}$. Esto último es tanto más grave si consideramos que los delitos en general y los de lesa majestad en particular son entendidos en el Estado confesional visigótico como auténticos crimina en virtud de la consideración de la ley como expresión de la justicia divina; y a la postre de la glorificación-sacralización del monarca, él mismo, como los obispos, también inviolable ${ }^{92}$. El rey es el ungido, cabeza del Reino diuine uoluntatis, y por tanto la traición del juramento debido al monarca no es la simple ruptura de un pacto entre particulares, por muy señalados que éstos sean, sino el incumplimiento de un mandato divino, un sacrilegium tal y como expresa con determinación el sínodo de Toledo del año 633, el llamado "concilio constituyente»" ${ }^{93}$.

Sin embargo, los obispos, tanto por su condición de líderes sociales como por su cercanía a los círculos de poder, participan y se ven involucrados en las vicisitudes y la turbulenta vida política del Reino Visigodo. En la larga lista de regicidios, usurpaciones y conjuraciones que configuran lo que Gregorio de Tours define como el morbus gothorum, resulta gratuito diferenciar la actuación de dirigentes laicos y eclesiásticos (salvo, naturalmente, en las aspiraciones tiránicas de los primeros). La conversión operada en 589, la mixtura de la población y la cooptación

90. Sobre el cesaropapismo visigótico, KING, Paul David: Derecho y sociedad en el reino visigodo. Madrid, Alianza, 1981, pp. 145-152.

91. Y sobre todo los obispos sancionaron y legitimaron los asaltos al poder, siempre que éstos resultaran triunfantes. Como bien expresa VALVerde CAStro, María del Rosario: Ideología, simbolismo y ejercicio del poder en la monarquía visigoda: un proceso de cambio. Salamanca, Ediciones Universidad de Salamanca, 2000, p. 247: «reiteraron su condena de alzamientos y conspiraciones contra el poder establecido y sancionaron luego sublevaciones triunfantes legalizando ascensiones ilegales al trono, o proclamaron la inviolabilidad del juramento de fidelidad al rey, eximiendo más tarde al pueblo de cumplir con él tras haber sido destronado por una conspiración victoriosa».

92. El concilio de Toledo del año 636 se dedica casi en su integridad a sancionar la inviolabilidad del monarca (en una protección religiosa que se mostró tan ineficaz como ya lo había sido en el pasado con los emperadores romanos). Siguiendo lo dispuesto en el Concilio IV de Toledo (a. 633), los delitos contra la corona son considerados anatema y penados con la excomunión. Es muy significativa de la pleitesía de los padres sinodales que concluyan la asamblea señalando que sólo el rey puede modificar lo dispuesto previamente y con un encendido elogio del rey Chintila (Con. $V$ Tol., c. 8 y 9).

93. Conc. IV Tol., c. 75. En este célebre canon se sentencia por tres veces anatema y exclusión de la Iglesia para quienes atenten contra el rey. Nótese que, contra toda verdad histórica, en la misma decisión sinodal se afirma que Suintila, teniendo sus propios scelera, había renunciado él mismo al trono. A cambio de estos servicios los obispos y nobles obtuvieron del rey Sisenando la limitación a las tendencias dinásticas de la corona (en principio sucesorio electivo nunca cumplido) y, en una contrapartida más práctica, un habeas corpus para el futuro. Tras este concilio, iluminado por la teología política isidoriana, un segundo impulso aún más decidido en el proceso de glorificación-sacralización de la corona visigoda data de los tiempos del rey Wamba, cuando se implanta la unción regia. Por tanto, aunque la sagrada unción no forma parte del ceremonial de entronización hasta los tiempos de Wamba, es evidente que la teología política que sacraliza al monarca es anterior. Al respecto, TEILLET, Suzanne: Des goths à la nation gothique. Les origines de l'idée de nation en Occident du Ve au VIIe siècle. Paris, Les Belles Lettres, 2001, pp. 507-519 y 596-621. 
aristocrática de los obispos, conforma un único grupo social dominante que comparte iguales intereses y aspiraciones: usurpar la corona en beneficio propio (los laicos para hacerse con la corona y los eclesiásticos para formar parte del círculo más próximo al nuevo monarca, con las previsibles ganancias que ello comportaba). Sin embargo, sí cabe diferenciar las consecuencias personales que tuvieron los intentos de atentar contra el rey y sus dominios, según sus protagonistas fuesen laicos o clérigos. De frustrarse sus planes, a los primeros les esperaba de común la muerte; a los segundos la relegación o el exilio. Nunca se consigna en nuestras fuentes el ajusticiamiento de un obispo, ni tan siquiera -hasta donde conozcosu muerte violenta por causas políticas en el Reino de Toledo.

Finalmente, no creo acertado colegir que la sacralidad otorgada a los obispos, y por consiguiente su inviolabilidad, contribuyó a la debilidad endémica del Reino Visigodo, propiciando o facilitando su participación activa en conjuras y regicidios; pero sí afirmar que la necesidad de ser juzgado por sus iguales ${ }^{94}$, y sobre todo la exención ante la pena de muerte, son unos privilegios ratione personae derivados de la consideración sagrada de su orden que sin duda compensaban las comunes, y en buena parte retóricas, definiciones del ministerio como una carga ${ }^{95}$, tal y como se pone de manifiesto con ocasión de conjuras e intentonas tiránicas.

94. Sobre los juicios sinodales, LETINIER Y MICHEL, Rosine: La función judicial de los concilios hispanos de la Antigüedad Tardía. León, Universidad de León, 1996. Naturalmente, es algo que no impide la sujeción de los obispos a la ley civil: KING, Paul David: op. cit., pp. 175-176.

95. La consideración del orden como un cargo (el propio priuilegium fori aparece en no pocos escritos episcopales como una pesada obligación) origina toda una retórica, derivada del mundo clásico, sobre resistencias a ser consagrado. Es algo compartido también por la corona. El ejemplo más emblemático al respecto es la aciter resistencia que opuso Wamba a su entronización, a decir de Julián de Toledo (lul., H.W., 2-3). 


\section{FUENTES:}

Búlgar (Epist. Wisigot. $n^{o}$ IO-I5):

Gil, Juan: Miscellanea Wisigothica. Sevilla, Universidad de Sevilla, I99I ( $2^{\mathrm{a}}$ ed.), pp. 30-43.

Concilios hispanos:

Martínez Díez, Gonzalo y Rodríguez, Félix: La Colección Canónica Hispana, vols. IV-VI. Madrid, CSIC, I984-2002.

VIVES, José: Concilios visigóticos e hispano-romanos. Barcelona-Madrid, CSIC, I963.

Continuatio Hispana (Cont. Hisp.):

Mommsen, Theodor: MGHaa XI-2. Berlin, I894, pp. 323-369.

Crónica Caesaraugustana (Chron. Caes.):

Mommsen, Theodor: MGHaa XI-2. Berlin, I894, pp. 22I-224.

Gregorio de Tours (H.F.):

KusH, Bruno y Levinson, Wilhelmus: MGHsrm I-I. Hannover, I96I.

HerRera RoldÁn, Pedro: Gregorio de Tours. Historias. Cáceres, Universidad de Extremadura, 2013.

Hidacio (Chron.):

TranoY, Alain: SC 2I8. Paris, I974.

Ildefonso de Toledo (Vir. Il.):

CodoÑer Merino, Carmen: El De Viris Illustribus de Ildefonso de Toledo. Estudio y edición crítica. Salamanca, Universidad de Salamanca, 1972.

Isidoro de Sevilla (Vir. Il., H.G., Ep. ad Hell. y De eccl. off.):

Codoñer Merino, Carmen: El De Viris Illustribus de Isidoro de Sevilla. Estudio y edición crítica. Salamanca, Universidad de Salamanca-CSIC, I964.

Rodríguez Alonso, Cristóbal: Las Historias de los Godos, Vándalos y Suevos de Isidoro de Sevilla. León, Centro de Estudios e Investigación San Isidoro, I975.

GUNDLACH, W.: MGHep. III-I. Berlin, I982, p. 66I.

Lawson, Christopher M.: CCSL II3. Turnhout, Brepols, I989.

Juan Crisóstomo (De sac.):

Migne, Jean-Paul: PG 48. Paris, I862, pp. 623-692.

Juan de Biclaro (Chon.):

CAmpos, Julio: Juan de Biclaro, obispo de Gerona. Su vida y su obra. Introducción, texto crítico y comentarios. Madrid, CSIC, I960.

Juicio entre Marciano y Avencio (Iud. inter Marc. et Avent. epsc.):

Martín IgLESIAS, José Carlos: «El ludicium inter Marcianum et Habentium episcopos (a. 638). Estudio, edición y traducción», Habis, 49 (2018), pp. 203-23I.

Julián de Toledo (H.W. y asociados):

Díaz y Díaz, Pedro Rafael: «Julián de Toledo: Historia del rey Wamba (traducción y notas)», Florentia Iliberritana, I (1990), pp. 84-II4.

LEvisON, Wilhelm: CCSL II5. Turnhout, Brepols, I976, pp. 2I7-255 (= MGHsrm V, pp. 500-535). 


\section{Leyes visigodas (L.V.):}

Ramis Serra, Pedro y Ramis Barceló, Rafael (eds.): El libro de los Juicios (Liber ludicorum). Madrid, Boletín Oficial del Estado, 2015.

Libellus Precum (Lib. prec.):

CANEllis, Aline: SC 504. Paris, Éditions du Cerf, 2006.

\section{Valerio de Bierzo (Ord. querim.):}

Díaz y Díaz, Manuel C.: Valerio del Bierzo. Su persona. Su obra. León, Centro de Estudios e Investigación San Isidoro, 2006, pp. 246-277.

\section{Vidas de los Padres emeritenses (VSPE):}

MAYA SÁnChEZ, Antonio: CCSL iI6. Turnhout, Brepols, I992.

Velázquez, Isabel: Vidas de los santos Padres de Mérida. Madrid, Trotta, 2008.

\section{Sisebuto (Vit.Desid.):}

DíAz y DíAz, Pedro R.: «Tres biografías latino medievales de San Desiderio de Viena (traducción y notas)», Fortunatae, 5 (1993), pp. 215-252.

MARTíN IgLESIAS, José Carlos: «Une nouvelle edition de la Vita Desiderii de Sísebut, acompagnée de quelques réflexions concernant la date des Sentetiae et du De viris illustribus d'Isidore de Séville», Hagiographica, 7 (2000), pp. I27-180.

\section{BIBLIOGRAFÍA:}

Bronisch, Alexander Pierre, «Precisiones sobre algunas informaciones históricas en la Crónica de Alfonso III», Edad Media. Revista de Historia, I2 (20II), pp. 37-4I.

Castillo Lozano, José Ángel y Molina Gómez, José Antonio, «El castigo aplicado al Tyrannus Argimundo según el Chronicon de Juan de Bíclaro», Potestas, 9 (2106), pp. 35-52.

Castillo Maldonado, Pedro: «In ecclesia contra ecclesiam: algunos ejemplos de disputas, violencias y facciones clericales en las iglesias tardoantiguas hispanas», Antiquité Tardive, 15 (2007), pp. 263-276.

Collins, Roger: «¿Dónde estaban los arrianos en el año 589?», en Concilio III de Toledo. XIV Centenario (589-1989). Toledo, Arzobispado de Toledo, I99I, pp. 2II-222.

Crouch, Jace, «The Judicial Punishment of Decalvatio in Visigothic Spain: a Proposed Solution based on Isidore of Seville and the Lex Visigothorum», The Mediterranean Review, 3-I (2010), pp. 59-77.

Díaz Martínez, Pablo C.: «Concilios y obispos en la Península Ibérica (siglos VI-VIII)», en Chiese locali e chiese regionale nell'Alto Medievo, Spoleto, Centro Italiano di Studi Sull'Alto Medievo, 20I4, pp. I095-II58.

Díaz Martínez, Pablo C.: "Quam ille de vita regis [...] consuluisset. Adivinación y violencia política en la Hispania visigoda», en Montero Herrero, Santiago y Perea Yébenes, Sabino: Adivinación y violencia en el mundo romano, Salamanca, Universidad de Salamanca, 2020, pp. 27I-292.

Díaz Martínez, Pablo C. y Fernández Ortiz de Guinea, Lina: «Valerio del Bierzo y la autoridad eclesiástica», Helmantica, I45-I46 (I997), pp. I9-35.

EsCRIBANo PaÑo, María Victoria: «Haeretici iure damnati: el proceso de Tréveris contra los priscilianistas (385)», en Cristianesimo e specifità regionali nel Mediterraneo latino (sec. 
IV-VI). XXII Incontro di studiosi dell'Antichità cristiana. Roma, Institutum Patristicum Augustinianum, 1994, pp. 393-4I6.

Fontaine, Jacques: «King Sisebut's Vita Desiderii and the Political Function of Visigothic Hagiography», en JAMES, Edward: Visigothic Spain: New Approaches. Oxford, Clarendon Press, I980, pp. 93-I29.

García Herrero, Gregorio: «Sobre la autoría de la Insultatio y la fecha de la composición de la Historia Wambae de Julián de Toledo», en Los visigodos y su mundo. Madrid, Comunidad de Madrid, I99I, I85-2I4.

García Moreno, Luis Agustín: Prosopografía del Reino Visigodo de Toledo. Salamanca, Universidad de Salamanca, I974.

García Moreno, Luis Agustín: Historia de España Visigoda. Madrid, Cátedra, I989.

García Moreno, Luis Agustín: «La oposición a Suintila: Iglesia, Monarquía y Nobleza en el Reino Visigodo», Polis, 3 (I99I), pp. 13-24.

García Moreno, Luis Agustín: España 702-719. La conquista musulmana. Sevilla, Universidad de Sevilla, 2013.

Isla Frez, Amancio: «Conflictos externos e internos en el fin del Reino Visigodo», Hispania: Revista española de historia, 2II (2002), pp. 6I9-635.

Isla Frez, Amancio: Ejército, sociedad y política en la Península Ibérica entre los siglos VII y XI, Madrid, 2010.

KING, Paul David: Derecho y sociedad en el reino visigodo. Madrid, Alianza, I98I.

LetINIER y Michel, Rosine: La función judicial de los concilios hispanos de la Antigüedad Tardía. León, Universidad de León, 1996.

Martin, Céline: La géographie du pouvoir dans l'Espagne visigothique. Villenueve d'Ascq, Press Universitaires du Septentrion 2003.

Martín Iglesias, José Carlos: «Julián de Toledo», en Codoñer, Carmen: La Hispania visigótica y mozárabe: dos épocas en su literatura. Salamanca, Ediciones Universidad de Salamanca, 20Io, pp. I55-I72.

Martín Iglesias, José Carlos, Díaz, Pablo C. y Vallejo Girvés, Margarita: La Hispania tardoantigua y visigoda en las fuentes epistolares. Antología y comentario. Madrid, CSIC, 2020 (con traducciones de diversas epístolas).

OrLANDIS, José: «Algunas consideraciones en torno a la circunstancia histórica de Valerio del Bierzo», Helmantica, I45-I46 (I997), pp. I53-163.

Pastor Muñoz, Mauricio, Corpus de Inscripciones Latinas de Andalucía IV: Granada. Sevilla, Junta de Andalucía, 2002.

PARra Romo, Ángela, «El ejército visigodo en campaña y la secesión de la Narbonense», Studia Historica. Historia Antigua, 36 (2018), pp. 22I-25I.

Petit, Carlos: «Crimen y castigo en el Reino Visigodo de Toledo», en Los visigodos y su mundo. Madrid, Comunidad de Madrid, I99I.

Salvador Ventura, Francisco: «La Historia Wambae de Julián de Toledo y sus caracteres de historiografía clásica», Habis, 50 (2019), pp. 39I-407.

STOcking, Rachel L.: «Martianus and Isidore: provincial councils in seventh-century Spain», Early Medieval Europe, 6-2 (1997), pp. I69-I88.

Teillet, Suzanne: «La déposition de Wamba. Un coup d'état au VII ${ }^{e}$ siècle», en Holtz, Louis y Fredoullle, Jean-Claude: De Tertullien aux Mozarabes. Mélanges offerts à Jacques Fontaine, t. II. Paris, Études Augustiniennes, I992, pp. 99-II3.

Telllet, Suzanne: Des goths à la nation gothique. Les origines de l'idée de nation en Occident $d u V^{e}$ au VII siècle. Paris, Les Belles Lettres, 200I.

Thompson, Edward A.: Los godos en España. Madrid, Alianza, ${ }^{2}$ I979. 
VALLEJO GiRvÉS, Margarita: «¿El éxito de un desterrado arriano?: la evangelización del obispo Sunna en Mauritania», en González Salinero, Raúl: Marginados sociales y religiosos en la Hispania tardorromana y visgoda. Madrid, Signifer Libros, 20I3, pp. I7I-I9I

Valverde Castro, María del Rosario: Ideología, simbolismo y ejercicio del poder en la monarquía visigoda: un proceso de cambio. Salamanca, Ediciones Universidad de Salamanca, 2000.

Valverde Castro, María del Rosario: Los viajes de los reyes visigodos de Toledo (53I-7II). Madrid, La Ergástula, 2017. 

Calidad de Revistas

científicas Españolas

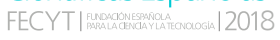

SERIE III HISTORIA MEDIEVAL

REVISTA DE LA FACULTAD DE GEOGRAFİA E HISTORIA
AÑO 2021

ISSN: 0214-9745

E-ISSN 2340-1362

\section{4 \\ issacio. \\ TIEMPO \\ Y FORMA}

\section{Volumen I}

\section{Artículos · Articles}

15 Patricia A. Argüelles Álvarez

Peligros, inseguridades y problemas del viajero visigodo

37 Carmen Barceló, Ana labarta, Josep Benedito \& José M. MELCHOR

Cuatro cerámicas con epigrafía árabe del Museu de Borriana

65 CARlos BARQuero Goñ

Organización de la Orden de San Juan en Castilla durante los siglos XII y XIII

113 Francisco de Paula Cañas Gálvez

Una infanta de Navarra en la corte de Castilla: escenarios políticos en torno a la configuración y evolución del Hostal y la casa de Blanca de Trastámara, Princesa de Asturias (1424-†1464)

\section{David Caramazana Malia}

Las promociones artísticas de Alonso de Ejea, arzobispo y administrador perpetuo de la Archidiócesis de Sevilla y patriarca de Constantinopla (1403-1417)

\section{Pedro Castillo Maldonado}

Privilegios episcopales: la inviolabilidad de los obispos visigóticos y el delito de lesa majestad

\section{MÁxIMO DIAGO HERNANDO}

Alonso de Fonseca, Obispo de Ávila, Cuenca y Osma, y el ascenso de un linaje de exiliados portugueses en la Castilla de los siglos XV y XVI

\section{Antonio PIO dI Cosmo}

Santa Brigida ed il Monte Gargano: un paesaggio dell'anima. La descrizione dell'ambiente come stratagemma d'ammaestramento morale

\section{FERRAN ESQUILACHE}

La 'fila' de agua valenciana y otras medidas de aforo. La verdadera naturaleza de un sistema de medición de caudales de origen andalusí

\section{Alejandro Esteban Álvarez}

Habices del Reino de Granada averiguados en 1528 y 1531: la țā'a nazarí de Órgiva (Alpujarra)

\section{JaVier Gómez Gómez \& IÑAKı MARTín VISO}

Rationes y decimas: evidencias sobre la gestión de las sernas en el siglo XI en el noroeste de la Península Ibérica
383 SANTIAGO GONZÁLEZ SÁNCHEZ

Aportaciones de Paredes de Nava a las campañas militares de Infante Don Fernando, señor de la villa y regente de Castilla, contra el Reino Nazarí de Granada en 1407 y en 1410

429 ANTONI LLIBRER ESCRIG

Una máquina para la industria medieval. Los batanes del sur valenciano: integración y negocio. Nuevas aportaciones (1490-1502)

455 José Miguel López Villalba Comunicación escrita y oral de la ordenanza municipa (siglos XV-XVI)

501 Emilio Martín Gutiérrez

El aprovechamiento de los recursos naturales: la grana en Andalucía occidental durante el siglo XV

\section{Volumen II}

537 VERA-CRuz Miranda MENACHO

$(1421-1461)$

Las finanzas de un heredero: Carlos de Aragón y Navarra

569 Raúl Morales Muñoz

Hacia una revalorización del conciliarismo hispano bajomedieval: el Defensorium Trium Conclusionum de Alfonso de Madrigal

605 David Nogales Rincón

Enrique III de Castilla (1390-1406) y la indagación de rentas: un proyecto regio para la búsqueda de mineros y tesoros a inicios de cuatrocientos

6.7.7 Gonzalo Oliva Manso

Seisenes y novenes. Tiempos de calma para la moneda castellano-leonesa (1282-1312)

685 Alberto Peña Fernández y Manuel García Alonso Una inscripción medieval inédita en la iglesia de San Miguel de Aguayo (Cantabria)

713 RODRIGO POUSA DIÉGUEZ

Configuración institucional de una villa costera: Muros en el tránsito de la Edad Media a la Edad Moderna

\subsection{JuAn A. Prieto Sayagués}

Las profesiones femeninas de la nobleza y de las oligarquías urbanas en la Castilla bajomedieval. Causas, dinámicas, privilegios y donaciones 


\section{4}

\section{ESPACIO,}

\section{TIEMPO}

Y FORMA

UกED

SERIE III HISTORIA MEDIEVAL

REVISTA DE LA FACULTAD DE GEOGRAFÍA E HISTORIA

815 María del Pilar Rábade Obradó

El miedo a la Inquisición en la Castilla de los Reyes Católicos

84.5 Carlos Manuel Reglero de la Fuente

EL abad contra el rey (y los regidores): conflicto de jurisdicciones y ejercicio del poder en Sahagún (1398-1417)

881 Manuel Alejandro Rodríguez de la Peña

Eusebius and Alcuin on Constantine and Charlemagne as Wise Rulers: Sapiential Rulership in Late Antiquity and the Early Middle Ages

9)15 Antonio SÁnCHEZ GonzÁlez

El Archivo de los Mariscales de Castilla y Marqueses de Malagón

\section{Estudios y comentarios}

9. 51 Serafín Olcoz Yanguas

Apostilla al estudio Influencia de las redes nobiliarias en la expansión cristiana del siglo XII: el caso de Soria (ETF, 33, 2020)

\section{Libros · Books}

969 CAstrillo CASAdo, Janire, Las mujeres vascas durante la Baja Edad Media (MARía Jesús Fuente)

973 Crónica del rey Juan II de Castilla. Minoría y primeros años de reinado (1406-1420) GARCIA, Michel (edición y estudio) (VÍctor MUÑ̃z GómEZ)

981 DA Silva, Marcelo Cândido, História Medieval (DIEgo CARLo AMÉNDOLLA SPÍNOLA)

9.87 Galende Díaz, Juan Carlos y Ávila SeoAne, Nicolás, El rodado regio hispánico. Fernando III de León y Castilla (12301252) (MAURICIO HERRERO JIMÉNEZ)

989 García IzQuierdo, Iván, Frontera, fuero y concejos. EI valle del Riaza en la Edad Media (siglos VIII-XII) (CARLOS BARQUERO GOÑI)

993 García IzQuierdo, Iván y Peterson, David (coords.), Camino y Señorío. Obra selecta de Luis Martínez García (ENRIQUe CANTERA MONTENEgRO)

995 GonzÁlez PAz, Carlos Andrés, O Bispado de Mondoñedo na Idade Media. Territorio, comunidade e poder (ENRIQUE CANTERA Montenegro) 


\section{4}

\section{ESPACIO,}

\section{TIEMPO}

Y FORMA

UกED

SERIE III HISTORIA MEDIEVAL

REVISTA DE LA FACULTAD DE GEOGRAFİA E HISTORIA

\section{Libros · Books}

9) López MARtínez, Amalia, Minutarios notariales de Estevo Pérez (Ourense, siglo XIV) (José MIgUel LóPEz VILLALBA)

999 Miranda García, Fermín y López de Guereño SAnz, María Teresa (eds.), La muerte de los príncipes en la Edad Media. Balance y perspectivas historiográficas (ANA ECHEVARRÍA ARSUAGA)

1003 Motis Dolader, Miguel Ángel, Vivencias, emocionesy perfiles femeninos. Judeoconversas e Inquisición en Aragón en el siglo XV (ANA ECHEVARría ARsuaga)

1007 Solórzano Telechea, Jesús Ángel y Martín PÉrez, Fernando (coords.), Rutas de comunicación marítima y terrestre en los reinos hispánicos durante la Baja Edad Media. Movilidad, conectividad y gobernanza (ENRIQUE JOSÉ RUIZ PILARES)

1013 TORRE, Sandra de la - ETXEBERRIA, Ekaitz - DíAz DE DURANA, José Ramón (coords.), Valer más en la tierra. Poder, violencia y linaje en el País Vasco bajomedieval (ENRIQUE CANTERA MONTENEGRO)

1015 TRILlo SAN José, Carmen, La Vega de Granada a partir de documentación árabe romanceada inédita (1457-1494). Estudio, edición e índices (INMACULADA GONZÁLEZ SOPEÑA)

1019 Val Valdivieso, M. ${ }^{a}$ Isabel - VillanueVa ZubizarReta, Olatz (Coords.), Pero Ansúrez. El conde, su época y su memoria (ENRIQUe CANTERA MONTENEGRO)

1021 Villanueva Morte, Concepción y Fernández de Córdova Miralles, Álvaro, El embajador Claver. Diplomacia y conflicto en las «Guerras de Italia» (1495-1504) (ENRIQUE Cantera Montenegro) 